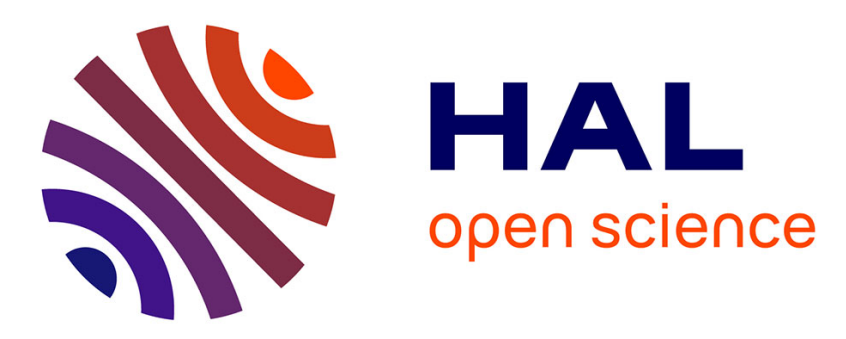

\title{
Double hydrophilic block copolymers self-assemblies in biomedical applications
}

\author{
Ayman El Jundi, Sytze Buwalda, Y. Bakkour, Xavier Garric, Benjamin \\ Nottelet
}

\section{- To cite this version:}

Ayman El Jundi, Sytze Buwalda, Y. Bakkour, Xavier Garric, Benjamin Nottelet. Double hydrophilic block copolymers self-assemblies in biomedical applications. Advances in Colloid and Interface Science, 2020, 283, pp.102213. 10.1016/j.cis.2020.102213 . hal-03097549

HAL Id: hal-03097549

https://hal.science/hal-03097549

Submitted on 5 Jan 2021

HAL is a multi-disciplinary open access archive for the deposit and dissemination of scientific research documents, whether they are published or not. The documents may come from teaching and research institutions in France or abroad, or from public or private research centers.
L'archive ouverte pluridisciplinaire HAL, est destinée au dépôt et à la diffusion de documents scientifiques de niveau recherche, publiés ou non, émanant des établissements d'enseignement et de recherche français ou étrangers, des laboratoires publics ou privés. 


\title{
Double hydrophilic block copolymers self-assemblies in
}

\section{biomedical applications}

\author{
Ayman El Jundi, ${ }^{1,2}$ Sytze J. Buwalda, ${ }^{1}$ Y. Bakkour, ${ }^{2}$ Xavier Garric, ${ }^{1}$ Benjamin Nottelet ${ }^{1 *}$
}

${ }^{1}$ IBMM, Univ Montpellier, CNRS, ENSCM, Montpellier, France

${ }^{2}$ Laboratory of Applied Chemistry (LAC), Faculty of Science III, Lebanese University, P.O. Box 826, Tripoli, Lebanon

* Corresponding author: benjamin.nottelet@umontpellier.fr

\begin{abstract}
$\underline{\text { Abstract }}$
Double-hydrophilic block copolymers (DHBCs), consisting of at least two different watersoluble blocks, are an alternative to the classical amphiphilic block copolymers and have gained increasing attention in the field of biomedical applications. Although the chemical nature of the two blocks can be diverse, most classical DHBCs consist of a bioeliminable non-ionic block to promote solubilization in water, like poly(ethylene glycol), and a second block that is more generally a pH-responsive block capable of interacting with another ionic polymer or substrate. This second block is generally non-degradable and the presence of side chain functional groups raises the question of its fate and toxicity, which is a limitation in the frame of biomedical applications. In this review, following a first part dedicated to recent examples of nondegradable DHBCs, we focus on the DHBCs that combine a biocompatible and bioeliminable non-ionic block with a degradable functional block including polysaccharides, polypeptides, polyesters and other miscellaneous polymers. Their use to design efficient drug delivery systems for various biomedical applications through stimuli-dependent self-assembly is discussed.
\end{abstract}

Keywords: Double-hydrophilic block copolymers; pH-responsive polymers; drug delivery systems; polyion complex micelles; degradable copolymers. 
Abbreviations: AA, alginic acid; AEM; 2-aminoethyl methacrylate; Alb, albumin; APEG, acryloyl end-capped PEG; API, active pharmaceutical ingredient; ATRA, all-trans retinoic acid; ATRP, atom transfer radical polymerization; BIC, block ionomer complex; $\gamma \mathrm{CAB} \varepsilon \mathrm{CL}, \gamma-$ (carbamic acid benzylester)- $\varepsilon$-caprolactone; CAC, critical association concentration; CL, caprolactone; ClCL, chloro $\varepsilon$-caprolactone; CLSM, confocal laser scanning microscope; CMC, critical micelle concentration; CMD, carboxymethyldextran; COSamf, chitooligosaccharides with 5-anhydro-D-mannofuranose at their reducing end; CytC, cytochrome C; Dex, dextran; DG, diammonium glycyrrhizinate; DHBCs, double-hydrophilic block copolymers; DHCs, double hydrophilic copolymers; DIM, diminazene diaceturate; DL, drug loading; DLS, dynamic light scattering; DOTA, 1,4,7,10-Tetraazacyclododecane-1,4,7,10-tetraacetic acid; DOX, doxorubicin; DPcZn, dendrimer phthalocyanine zinc; DPP, diphenyl phosphate; DS, degree of substitution; DTT, dithiothreitol; EE, encapsulation efficiency; FA, folate ; FACS, flow cytometry analysis; $\mathrm{Gd}$ and $\mathrm{Gd}^{3+}$, gadolinium and gadolinium ion; GlcN, $(1 \rightarrow 4)$-linked units of 2-amino-2-deoxy- $\beta$-D-glucopyranose; HA, hyaluronic acid; LA, D,L-lactic acid; LacPEG, lactose-conjugated PEG; MA, methacrylic acid; MAL, L-malic acid; MH, minocycline hydrochloride; mPEG, methoxy-poly(ethylene glycol); MRI, magnetic resonance imaging; MSA, mercaptosuccinic acid; MSC, mesenchymal stem cell; MTT, methotrexate; MTX, mitoxantrone; NAEP, 2-(N-acryloyloxy) ethylpyrrolidone; NMP, N-(2-methacryloylxyethyl) pyrrolidone; NPs, nanoparticles; NVPI, N-vinylphthalimide; PAA, poly(acrylic acid); PAEAPI, $\quad \operatorname{poly}(\beta$-aminoester)-1-(3-aminopropyl)imidazole; $\quad$ PAEP, $\quad \operatorname{poly}((2-(2-$ aminoethoxy)ethoxy) phosphazene); PAMPS, poly(2-acrylamido-2-methyl-1-propanesulfonic acid); PAMPSNa, poly(sodium 2-acrylamido-2-methylpropanesulfonate); PAPTAC, poly(3acrylamidopropyltrimethylammonium chloride; PAsp, poly(L-aspartic acid); PAsp(DET), poly(L-aspartic acid) bearing a N-(2-aminoethyl)-2-aminoethyl group; PATMC, poly(5allyloxytrimethylethylenecarbonate); $\mathrm{PBYPCOOH}$, poly(phosphotriester)s bearing pendent carboxylic acids; PCCL, poly(6-acetoxyl- $\varepsilon$-caprolactone); PCEtOx, poly(2-carboxyethyl-2oxazoline); PCL, poly( $\varepsilon$-caprolactone); P(CL-co-DCL), poly( $\varepsilon$-caprolactone-co- $\gamma$-dimethyl maleamidic acid- $\varepsilon$-caprolactone); PDEAEMA (poly(2-(diethylamino)ethyl methacrylate); PDMAEMA, poly(2-(dimethylamino)ethyl methacrylate); PDT, photodynamic therapy; PEC, polyelectrolyte complexes; PEG, poly(ethylene glycol); PEGMA, polyethylene glycol methacrylate; PEI, poly(ethyleneimine); PEO, poly(ethylene oxide); PEtOx, poly(2-ethyl-2oxazoline); PGlu, poly(L-glutamic acid); PIC, polyion complex; PiPrOx, poly(2-isopropyl-2- 
oxazoline); PLL, polylysine; PMA, poly(methacrylic acid); PMMA, poly(methyl methacrylate); P2MVP, poly(N-methyl-2-vinyl pyridinium iodide); PNiPAM, poly(Nisopropylacrylamide); $\mathrm{PPDO}^{-}$, poly(phosphodiester)s with a negatively charged oxygen atom; PPIL, poly(4-N-piperilactone); PPLG, poly( $\gamma$-propargyl-L-glutamate); PSar, poly(sarcosine); PSMA, poly(styrene-alt-maleic anhydride); Pul, pullulan; PVA, poly(vinyl alcohol); PVAc, poly(vinyl acetate); PVAm, Poly(vinyl amine); PVCL, Poly(N-vinylcaprolactam); PVP, Poly(vinyl pyrrolidone); RAFT, reversible addition-fragmentation chain transfer; Rh, hydrodynamic radius; ROP, ring opening polymerization; ROS, reactive oxygen species; $\mathrm{sCT}$, salmon calcitonin; siRNA, small interfering ribonucleic acid; SLS, static light scattering; TEM, transmission electron microscopy; TMC, trimethyl chitosan.

\section{Contents}







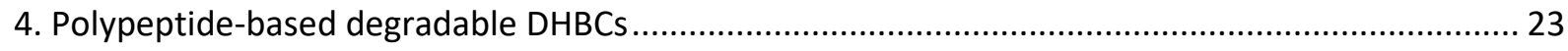

5. Polyester-based degradable DHBCs and others miscellaneous synthetic blocks ........................... 32

6. DHBCs for biomedical applications: unique advantages, current challenges and future perspectives



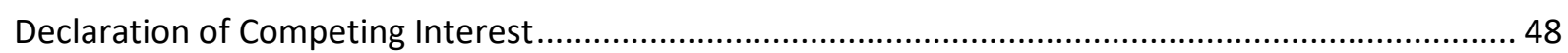

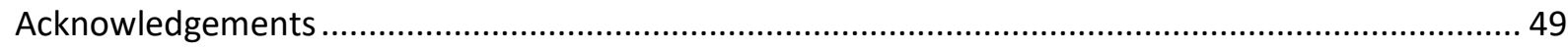

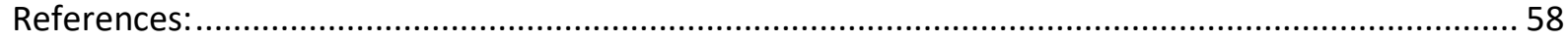

\section{Introduction}

Block copolymers are a category of polymers in which the macromolecule consists of two or more distinct blocks of homopolymer. Block copolymers with two, three, and more blocks are called diblock, triblock, and multiblock copolymers respectively. Block copolymers can be further classified according to their architectural arrangement. For example, linear or star shaped block copolymers can be synthesized. The number of polymer types in block 
copolymers may be equal to or lower than the number of blocks. For example, triblock copolymers may be constituted of three polymers ( $\mathrm{ABC}$ triblock copolymers) or two polymers (ABA triblock copolymers).

The nature of the constituting blocks (hydrophilic or hydrophobic) gives rise to a further categorization within block copolymers. Amphiphilic block copolymers, which consist of at least one hydrophilic and one hydrophobic block, may self-assemble in water to form micelles or aggregates with a hydrophobic core surrounded by a hydrophilic shell. Micelles prepared from amphiphilic block copolymers have been studied primarily as controlled drug delivery systems as their hydrophobic core may serve as a depot for the solubilization of clinically relevant doses of hydrophobic drugs, as reviewed in several excellent publications [1-3].

In the last two decades, double-hydrophilic block copolymers (DHBCs), consisting of two or more water-soluble blocks of different chemical nature, have gained increasing attention. In many DHBCs one block (often based on poly(ethylene glycol) (PEG) or poly(ethylene oxide) (PEO)) only promotes solubilization in water, whereas the other block is responsive to an external stimulus or capable of interacting with another polymer or substrate. In aqueous solution under normal conditions, the two hydrophilic blocks are well solvated and DHBCs behave like water-soluble polymers with no amphiphilic characteristics. However, a variation of temperature, ionic strength or $\mathrm{pH}$, as well as a complexation reaction may change the hydrophilicity of one of the homopolymer blocks into hydrophobicity, thereby introducing amphiphilicity, which in turn may lead to the formation of functional structures such as micelles.

Although the first synthesis of a DHBC dates back to 1972 [4], only during the last two decades the potential of DHBCs has been fully recognized for various applications. These include for example crystal growth modification, metal oxide particle stabilization, nanoparticle fabrication, controlled drug delivery and gene transfection (Scheme 1). 


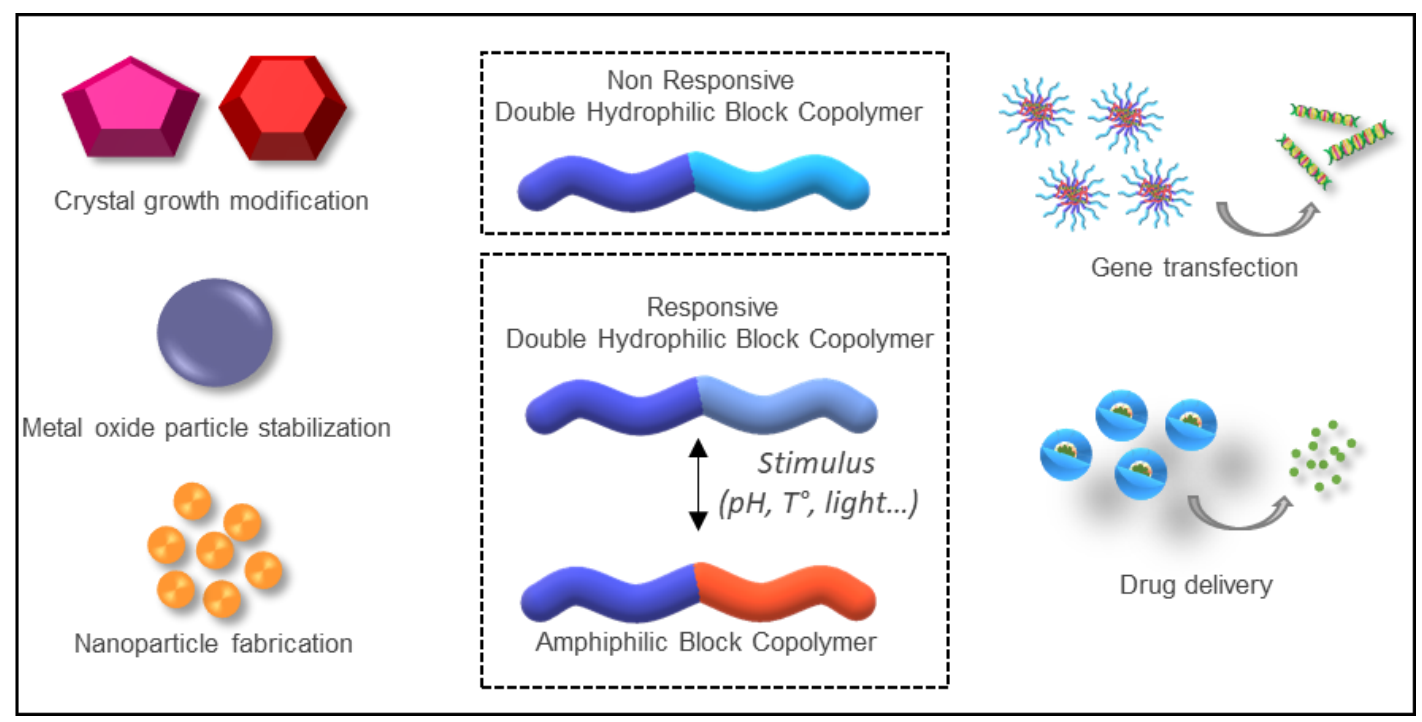

Scheme 1. Different type of double hydrophilic block copolymers and their applications.

Despite the increasing interest for this unique class of polymers, recent reviews dedicated to DHBCs are scarce. A comprehensive review concerning DHBCs dates back as far as 2001 [5]. Since then, a limited number of reviews have been published relating to the self-assembly processes of DHBCs, including recent examples of polyion complex (PIC) [6] and block ionomer complex (BIC) micelles [7] (Scheme 2), as well as a recent review dedicated to the self-assembly of completely water-soluble DHBCs in aqueous medium without application of external stimuli but at high concentration [8].

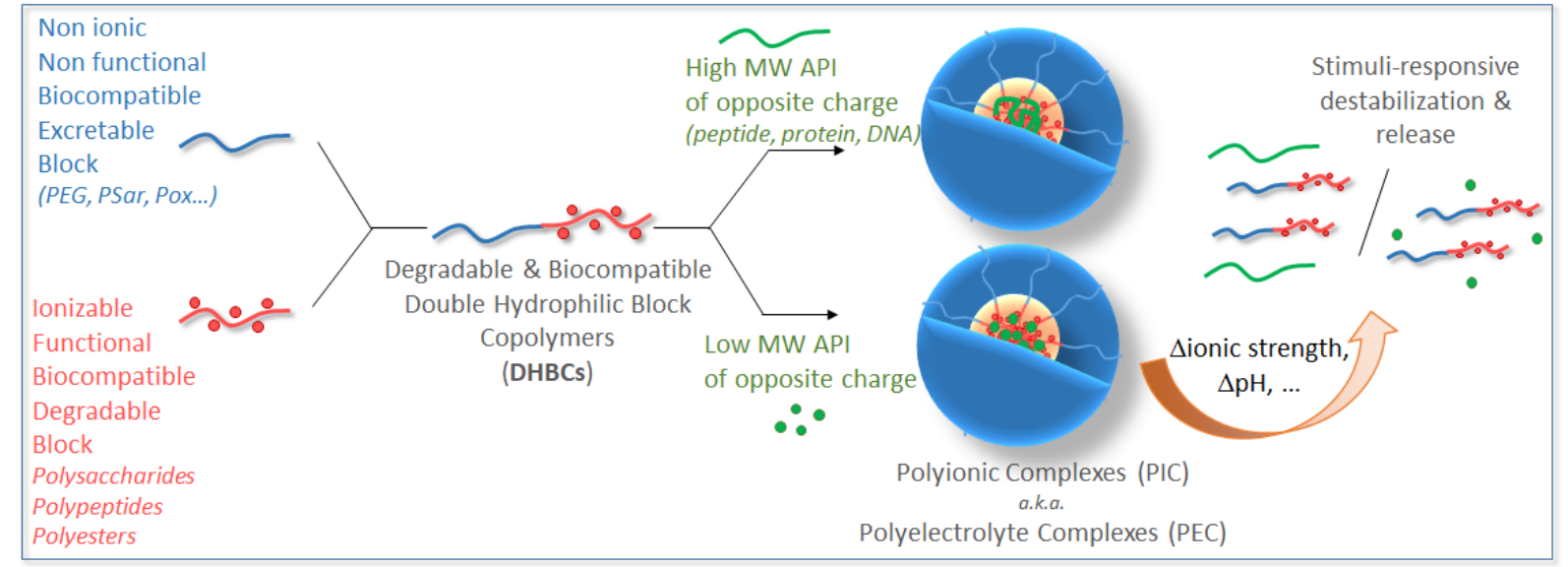

Scheme 2. Formation of Polyionic Complexes (PIC) (also known as Polyelectrolyte Complexes (PEC)) based on degradable double hydrophilic block copolymers. 
The present review differs from these previous contributions as we aim at reporting and summarizing recent studies dedicated to the synthesis and the study of the behaviour of DHBCs in solution for biomedical applications. After discussing some recent examples of nondegradable DHBCs, and because biodegradability is in our view of first importance for biomedical polymers, we will subsequently categorize the various degradable DHBCs according to the chemical nature of the responsive or interacting polymer block of the DHBC. We will successively discuss DHBCs which contain polysaccharides, polypeptides, polyesters and other miscellaneous degradable blocks as functional blocks (Table 1). All these polymers are considered biodegradable and bioresorbable as they degrade to non-toxic products in vivo which can be excreted by the kidneys. Despite the existence of other alternatives (poly(2oxazoline), poly(vinyl pyrrolidone) etc...), they are mostly combined with PEG as a solubilizing block due to its long track record in pharmaceutical formulation, its excretability via the renal pathway up to a molecular weight (MW) of approximately $30 \mathrm{~kg} / \mathrm{mol}$ [9], and its medium to long-term biodegradability [10,11]. Finally, in a last part we will discuss the main biomedical applications taking advantage of these DHBCs and we will emphasize the remaining challenges and future perspectives associated with this class of copolymers.

\section{Non-degradable DHBCs}

Many of the non-degradable DHBCs reported in literature are based on a PEG block associated with a poly(acrylic acid) (PAA) or a poly(methacrylic acid) (PMA) block for the anionic ones, or poly(dimethylaminoethyl methacrylate) (PDMAEMA), and poly(ethylenimine) (PEI) for the cationic ones (Table 1). This type of copolymer offers the advantages of a straightforward synthesis as well as pH-responsiveness. Apart from PEG, also poly(vinyl pyrrolidone) (PVP), poly(vinyl caprolactam) (PVCL), poly(vinyl alcohol) (PVOH), poly(vinyl amine) (PVAm) and poly(oxazoline) (POx) have been used as water-soluble block in combination with different 
responsive blocks. In the following paragraph examples of such non-degradable DHBCS proposed in various recent biomedical applications are discussed. A summary of the type of self-assemblies obtained with these DHBCs and their characteristics is provided in Table 2.

Shin et al. reported on giant polymer vesicles (diameter 5-8 $\mu \mathrm{m}$ ) which formed via selfassembly of double-hydrophilic PEG-PAA diblock copolymers at $\mathrm{pH} 2$. This was attributed to protonation of the carboxylic groups on the PAA block (pKa of 4.5), thereby providing hydrogen bonding with itself and the PEG block resulting in aggregation of the polymer chains, thus providing a mechanism for phase segregation of the complex of otherwise soluble polymers. In contrast, no vesicle formation was observed at $\mathrm{pH}$ 9. To demonstrate that the polymer vesicles enable the triggered delivery of cargo molecules, Alexa Fluor 488 was incorporated by rehydrating the polymer film with a solution of the hydrophilic fluorophore at $\mathrm{pH}$ 2. Upon increase of the $\mathrm{pH}$ above 4.5, the encapsulated fluorophore was rapidly and completely released within 30 min due to dissociation of the vesicles [12].

Frangville et al. reported on nanoparticles of PEG-PAA crosslinked by gadolinium $\left(\mathrm{Gd}^{3+}\right)$ ions and their use as magnetic resonance imaging (MRI) contrast agents. The formation of the hybrid inorganic/polymeric nanoparticles (20 nm in diameter) was ascribed to association between $\mathrm{Gd}^{3+}$ ions and negatively charged acrylic acid monomer units in the core, which is surrounded by a PEG corona. The integrity of the NPs was maintained even after significant dilution and over a large range of $\mathrm{pH}$ and ionic strength values. This was explained by the entanglement of PAA blocks, resulting in additional crosslinks that stabilize the nanoparticle. In vivo experiments showed that the $\mathrm{Gd}^{3+}$ / PEG-PAA nanoparticles provide both a higher intensity and a more persistent enhancement of vascular MRI signals, at one-third of the total Gd concentration of the commercially available contrast agent GdDOTA [13].

Raisin et al. reported the design of tripartite PIC micelles as original non-viral polymeric vectors suited for mesenchymal stem cell transfection with small interfering ribonucleic acid 
(siRNA) using the non-degradable DHBC PEO- $b$-PMA. The formation of PIC micelles is based on the association of the DHBC with a cationic homopolymer (polylysine (PLL) or poly(ethyleneimine) (PEI)), and the siRNA can be associated with the core of micelles by complexation with the cationic polymer. The micelle formulations were designed to exhibit $\mathrm{pH}-$ triggered disassembly in an acidic $\mathrm{pH}$ range found in endosomes. The tripartite micelles were non-cytotoxic and exhibited an ability to deliver a siRNA targeting Runx2 and to induce efficient gene silencing in murine MSC [14].

In another example, Ramasamy et al. investigated the interaction of the cationic drugs doxorubicin (DOX) and mitoxantrone (MTX) with the anionic DHBC PEO- $b$-PAA. The primary amino group of DOX and two secondary amino groups of MTX were responsible for electrostatic interactions with the ionized carboxyl group (pKa $\sim 5)$ of PEO-b-PAA. The drug loading (DL) was $45 \mathrm{wt} \%$ for MTX and $70 \mathrm{wt} \%$ for DOX. A faster release of the two drugs was observed at $\mathrm{pH} 5$ (typical of the environment of cancer cells) compared to the release at physiological pH (7.4). DOX PIC micelles showed a higher cellular uptake than MTX PIC micelles. Both complexes induced apoptosis of cancer cells and suppressed tumour growth to the same level as the respective free drugs, but they exhibited a prolonged blood circulation [15].

Poly(vinyl pyrrolidone) (PVP) is another example of non-ionic water-soluble block that has been used to prepare non-degradable DHBCs. PVP is largely used in pharmaceutical formulations due to its cytocompatibility and strong binding capacity via dipole interactions with drugs [16]. The next paragraph gathers the few recent examples of PVP analogues used to prepare DHBCs with a ionisable block. Gao et al. reported on a series of PVP-based DHBCs prepared by RAFT polymerization for drug delivery applications through the formation of PIC micelles with different drugs including coenzyme A and folic acid. This series of DHBCs embedded PVP- $b$-poly(styrene-alt-maleic anhydride) (PVP- $b$-PSMA), PVP- $b$-poly(2- 
(dimethylamino)ethyl methacrylate) (PVP- $b$-PDMAEMA) and PVP- $b$-poly(2-acrylamido-2methyl-1-propanesulfonic acid) (PVP-b-PAMPS) [17-19]. Another example consists of PVP$b$-PMA also obtained by RAFT polymerization and used to control calcium carbonate $\left(\mathrm{CaCO}_{3}\right)$ morphologies with target applications in biomimetic mineralization [20]. More recently, Destarac et al. reported on another series of PVP-based DHBCs obtained by redox initiated aqueous RAFT/MADIX polymerization. This approach resulted in the synthesis of PVP- $b$ PAA, PVP- $b$-poly(sodium 2-acrylamido-2-methylpropanesulfonate) (PVP- $b$-PAMPSNa), and PVP- $b$-poly(3-acrylamidopropyltrimethylammonium chloride) (PVP- $b$-PAPTAC) foreseen for use in drug delivery and biological inorganic phase templating [21]. Another recent example of potential interest for the design of drug vectors includes a vinyl pyrrolidone analogue, namely 2-(N-acryloyloxy)ethylpyrrolidone (NAEP). NAEP was copolymerized by reversible additionfragmentation chain transfer (RAFT) polymerization with 2-(diethylamino)ethyl methacrylate (DEAEMA) to yield PNAEP- $b$-PDEAEMA DHBCs that can lead to the formation of $\mathrm{pH}$ responsive micelles [22]. In the same family of analogue, N-(2-methacryloylxyethyl) pyrrolidone (NMP) was copolymerized by RAFT polymerization with MA to prepare a family of well-controlled DHBCs able to stabilize and control the size of gold nanoparticles, that are largely used in biomedical applications [23], in a pH-dependent manner [24].

Poly(N-vinylcaprolactam) (PVCL) is also used for biomedical applications as a non-ionic water-soluble polymer. It is for example present in the BASF excipient Soluplus ${ }^{\circledR}$ that is proposed to formulate insoluble drugs. As such recent examples of PVCL-based DHBCs have been reported. Liang et al. prepared well-defined DHBCs of PVCL and PVP via RAFT polymerization [25]. PVCL is a thermoresponsive polymer with superior biocompatibility in comparison with PNiPAM [26]. The LCST could be lowered by increasing the PVCL segment length and raised by increasing the hydrophilic PVP segment length. Below the LCST the copolymers dissolved completely in aqueous solution, whereas they formed spherical micellar 
or vesicular morphologies above the LCST. The size of the self-assembled structures could be controlled via the molar ratio of the PVCL and PVP segments. The PVCL- $b$-PVP copolymers showed non-toxic towards cancer cells. The group of Jerome reported on the cobalt-mediated radical polymerization of VCL initiated from a poly(vinyl acetate) (PVAc) based macroinitiator to yield PVAc- $b$-PVCL block copolymers [27]. These amphiphilic copolymers were subsequently hydrolysed to give poly(vinyl alcohol)- $b$-PVCL (PVA- $b$-PVCL) DHBCs. These polymers became amphiphilic when heated above their LCST in aqueous solution $\left(36-42{ }^{\circ} \mathrm{C}\right.$, depending on their composition) due to dehydration of the PVCL sequence, leading to selfassembled spherical aggregates with a collapsed PVCL core and a soluble PVOH shell. In a follow-up paper the authors used the PVA- $b$-PVCL DHBCs to prepare nanogels by crosslinking the PVA corona above the LCST with a redox-responsive crosslinking agent [28]. The nanogels loaded with the hydrophobic model drug Nile red (NR) had sizes ranging from 50 to $100 \mathrm{~nm}$ and were able to release NR in the presence of the reducing agent dithiothreitol (DTT) thanks to cleavage of the disulphide bonds in the crosslinker (Figure 1a and 1b). In addition, the nanogels proved to be cytocompatible towards L929 fibroblasts and to be efficiently uptaken by MEL-5 cancer cells (Figure 1c), which show the potential of the PVA-b-PVCL nanogel system for intracellular drug release. 
(a)
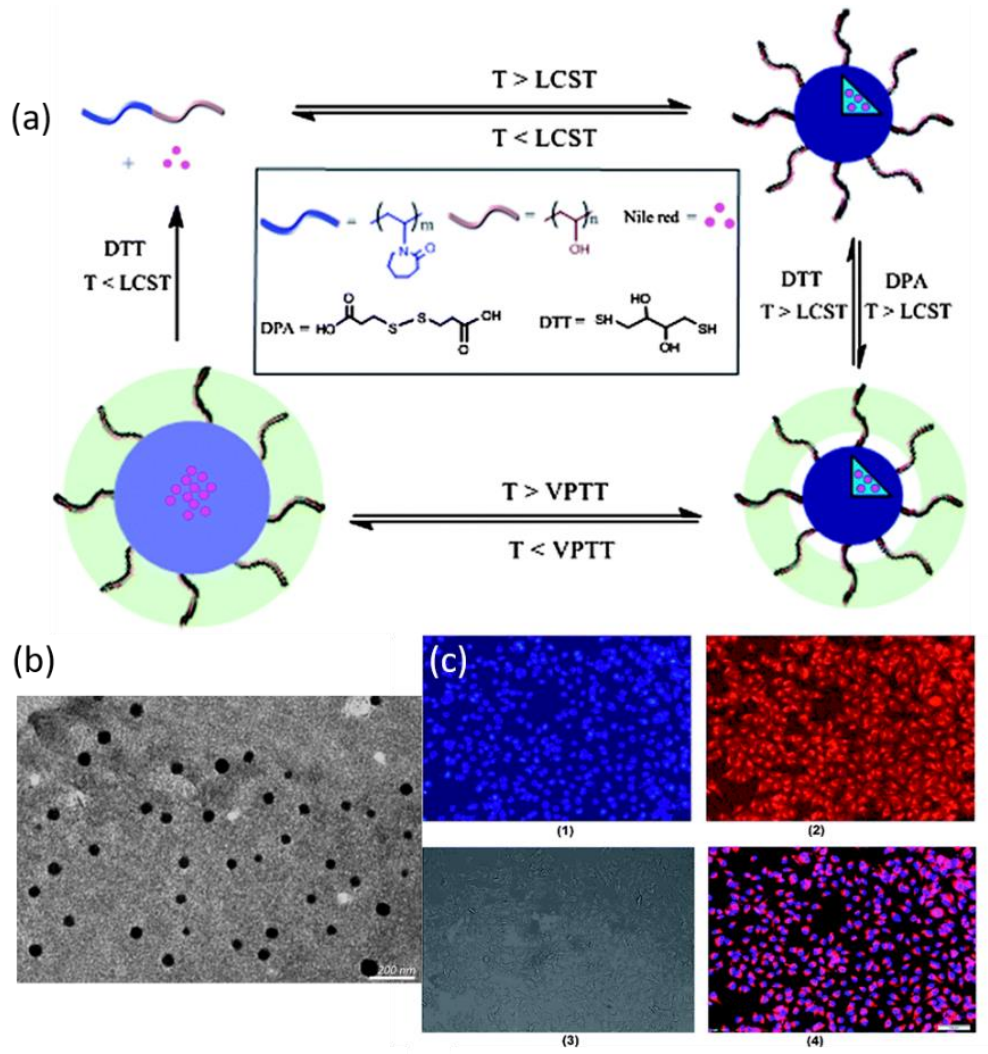

Figure 1. (a) Schematic illustration of the preparation, dissociation of PVA- $b$-PVCL crosslinked nanogels, loading of Nile red (NR) and redox-triggered release behaviors (LCST: lower critical solution temperature, VPTT: volume phase transition temperature) ; (b) TEM images of the crosslinked nanogels (scale bar $200 \mathrm{~nm}$ ) ; (c) Fluorescence microscopy images of the treated MEL-5 cells after $24 \mathrm{~h}$ incubation with the NR-loaded nanogel : (1) nuclei stained with DAPI (blue), (2) fluorescence pattern of NR (red), (3) contrast field pattern, (4) merged images of (1), (2) and (3) (scale bar: $100 \mathrm{~mm}$ ) (adapted with permission from [28]).

This last example illustrates the use of PVCL in DHBCs, but also of PVA that is another example of non-ionic water-soluble polymer. Cobalt-mediated radical polymerization was also used for the preparation of PVA- $b$-PVP DHBCs [29] as well as pH-responsive PVA- $b$-PAA DHBCs [30]. The latter self-assembled into aggregates below pH 3 due to the protonation of the PAA carboxylic acid groups, which decreases PAA solubility and enables hydrogen bonding between PAA and PVA blocks. Moreover, PVA- $b$-PAA formed PIC micelles with poly(N-methyl-2-vinyl pyridinium iodide)- $b$-poly(ethylene oxide) (P2MVP- $b$-PEO) DHBCs at pH 8 through electrostatic interactions between the core-forming P2MVP and PAA blocks [31]. In the same family of vinyl polymers, Maki et al. prepared DHBCs having poly(vinyl amine) 
(PVAm) blocks via sequential RAFT polymerization of $\mathrm{N}$-vinylphthalimide (NVPI) and NiPAM, followed by deprotection of the PNVPI block [32]. Aqueous solutions of amphiphilic PNVPI- $b$-PNiPAM block copolymers and PVAm- $b$-PNiPAM DHBCs exhibited a LCST type phase transition between $25-32{ }^{\circ} \mathrm{C}$ and $53-75^{\circ} \mathrm{C}$, respectively, in accordance with the higher hydrophilicity of the PVAm- $b$-PNiPAM DHBCs. Although micelle formation was hypothesized for the block copolymers above the LCST, no characterization of these micelles was provided.

Poly(2-oxazoline)s (POx) are an important class of polymers that focuses a strong interest as they have been proposed as alternative to PEG in biomedical applications thanks to their tunable physicochemical properties, good water solubility and excellent biocompatibility [33]. As debates regarding their degradability are still ongoing [34], we chose in this review to present most POx-based DHBCs in this part dedicated to non-degradable DHBCs. Examples of POx DHBCs containing a second block of well-recognized degradability can be found in the corresponding subparts. Zschoche et al. prepared a series of di- and triblock copolymers with temperature-sensitive poly(2-isopropyl-2-oxazoline) ( $\mathrm{PiPrOx}$ ) blocks and $\mathrm{pH}$-sensitive poly(2carboxyethyl-2-oxazoline) (PCEtOx) blocks [35]. The temperature- and $\mathrm{pH}$-induced reversible phase transition converted these DHBCs into amphiphilic polymers allowing for self-assembly in aqueous solution. The temperature and $\mathrm{pH}$ values of the transitions as well as the nature of the formed aggregates (micelles or vesicles) could be controlled via the size and arrangement of the individual blocks. Other examples of POx-containing DHBCs include PEG- $b$-PEtOx star block copolymers [36], PEG- $b$-poly(2-methyl-2-oxazoline) diblock copolymers [37] and PEtOx- $b$-PVP diblock copolymers [38]. In these cases, no application was foreseen and studies aimed at studying the self-aggregation of these DHBCs that was observed without the 
application of an external stimulus, suggesting that even in DHBCs subtle differences in hydrophilicity among the constituting blocks are sufficient to drive polymer aggregation.

As shown in this part, polyethers (PEG, PEO), vinyl polymers (PVP, PVCL, PVA...) and poly(2-oxazoline)s (PEtOx) are the non-ionic blocks classically used in non-degradable DHBCs. More exotic blocks like polydehydroalanine to yield PEG- or poly(acrylic acid)- $b$ polydehydroalanine DHBCs [39,40], synthetic glycopolymers in PEG- $b$-poly(mannose) [41], or poly((4-diethylamino)-(E)-stilbene)-alt-maleic acid)-b-poly(acryloyl morpholine) have been reported [42]. However, they remain largely unexploited in comparison to these classical families. In addition, and although the DHBCs discussed in this part represent promising systems that can potentially address several challenges in the biomedical domain, their nondegradability remains an issue as the polymers may accumulate in the body or, if elimination is possible, in the environment [43]. Therefore, in the remainder of this review we focus on degradable DHBCs containing polysaccharides, polypeptides or polyesters as functional blocks associated with biocompatible non-ionic and bioeliminable blocks, mainly PEG and PEtOx, whereas other non-ionic blocks raising concerns of potential toxicity, like PNiPAM, are not considered. 
Table 2: Characteristics of the self-assemblies obtained with non-degradable double hydrophilic block copolymers.

\begin{tabular}{|c|c|c|c|c|c|}
\hline \multirow{2}{*}{ DHBC } & \multicolumn{3}{|c|}{ Self-assemblies } & \multirow[t]{2}{*}{ Stability $^{a}$} & \multirow[t]{2}{*}{ Ref. } \\
\hline & Type & Preparation & Characteristics $^{\mathrm{a}}$ & & \\
\hline PEO- $b$-PAA & Giant vesicles & $\begin{array}{l}\text { gel-assisted rehydration } \\
\text { method at } \mathrm{pH} 2.3\end{array}$ & $\begin{array}{l}\mathrm{D}_{h} \sim 5-8.0 \mu \mathrm{m} / \xi \text { potential -11 } \\
\mathrm{mV} \text { (at } \mathrm{pH} 2.4 \text { ) }\end{array}$ & ass. $<\mathrm{pH} 4.5<$ disass. & [12] \\
\hline PEO- $b$-PAA & $\begin{array}{l}\mathrm{Gd}^{3+}-\text { loaded PIC } \\
\text { micelles }\end{array}$ & $\begin{array}{l}\text { addition of } \mathrm{Gd}^{3+} \\
\text { solution to } \mathrm{PEO}-b \text {-PAA } \\
0.1 \mathrm{wt} \% \text { solution }(\mathrm{R}=1)\end{array}$ & $\mathrm{D}_{h} \sim 33 \mathrm{~nm} / \xi$ potential $\sim 0 \mathrm{mV}$ & $\begin{array}{l}\text { disass. }<\mathrm{pH} 4 . \\
\text { stable for DHBC } \\
\text { concentrations of } 0.1-10^{-4} \mathrm{wt} \% \\
\text { stable at } 1 \mathrm{M} \mathrm{NaCl} .\end{array}$ & [13] \\
\hline PEO- $b$-PMA & $\begin{array}{l}\text { SiRNA-loaded PIC } \\
\text { micelles }\end{array}$ & $\begin{array}{l}\text { (PLL/SiRNA) solution } \\
\text { added to PEO- } b \text {-PMA } \\
\text { solution }(\mathrm{R}=1)\end{array}$ & $\begin{array}{l}\mathrm{D}_{h} \sim 37-53 \mathrm{~nm} / \xi \text { potential } \sim 3.5 \\
\text { to } 7.9 \mathrm{mV} \text { (in water) and } \mathrm{D}_{h^{\sim}} \\
101 \mathrm{~nm} \text { (in PBS) / EE } 90 \%\end{array}$ & disass. < pH 6. & {$[14]$} \\
\hline PEO- $b$-PAA & $\begin{array}{l}\text { DOX- or MTX- } \\
\text { loaded PIC } \\
\text { micelles }\end{array}$ & $\begin{array}{l}\text { mixing of drug and } \\
\text { polymer aqueous } \\
\text { solutions for } 24 \mathrm{~h}(\mathrm{D} / \mathrm{P} \\
=0.25 \text { or } 0.5)\end{array}$ & $\begin{array}{l}\mathrm{D}_{h} \sim 100 \mathrm{~nm} / \xi \text { potential } \sim 5 \text { to }- \\
35 \mathrm{mV} \text { (at } \mathrm{pH} \text { 7) / EE } \sim 90 \% / \\
\mathrm{DL} \sim 45 \% \text { (MTX) } \sim 70 \%\end{array}$ & drug release at pH 5. & {$[15]$} \\
\hline $\begin{array}{l}\text { PVP- } b \text {-PSMA \& } \\
\text { PVP- } b \text {-PDMAEMA }\end{array}$ & $\begin{array}{l}\text { Co A-loaded PIC } \\
\text { micelles }\end{array}$ & $\begin{array}{l}\text { mixing of PVP- } b \text {-PSMA } \\
\text { and PVP- } b \text {-PDMAEMA } \\
\text { / Co A solutions, pH } \\
\text { neutralization, dialysis }\end{array}$ & $\begin{array}{l}\mathrm{D}_{h} \sim 100-130 \mathrm{~nm} / \mathrm{EE} \sim 60 \% / \\
\mathrm{DL} \sim 10-29 \%\end{array}$ & $\begin{array}{l}\text { drug release at } \mathrm{pH} 2<\mathrm{pH} 9< \\
\mathrm{pH} 7.4 \text {. }\end{array}$ & {$[17]$} \\
\hline $\begin{array}{l}\text { PVP- } b \text {-PAMPS \& } \\
\text { PVP- } b \text {-PDMAEMA }\end{array}$ & $\begin{array}{l}\text { FA-loaded PIC } \\
\text { micelles }\end{array}$ & $\begin{array}{l}\text { mixing of PVP- } b- \\
\text { PAMPS/FA and PVP- } b- \\
\text { PDMAEMA solutions, } \\
\text { pH neutralization, } \\
\text { dialysis }\end{array}$ & $\begin{array}{l}\mathrm{D}_{h} \sim 170 \mathrm{~nm} / \mathrm{EE} \sim 85 \% / \mathrm{DL} \sim \\
21 \%\end{array}$ & drug release at $\mathrm{pH} 9 \geq \mathrm{pH} 7.4$ & [19] \\
\hline PVP- $b$-PMA & $\begin{array}{l}\text { templating of } \\
\mathrm{CaCO}_{3}\end{array}$ & $\begin{array}{l}\text { injection of } \mathrm{Na}_{2} \mathrm{CO}_{3} \text { in } \\
\text { PVP- } b \text {-PMA solution, } \\
\text { pH adjustment at } 10, \\
\text { addition of } \mathrm{CaCl}_{2}\end{array}$ & $\begin{array}{l}\text { rhombohedral or mutilayered } \\
\mathrm{CaCO}_{3} \text { calcite microcrystals }\end{array}$ & not applicable. & {$[20]$} \\
\hline
\end{tabular}




\begin{tabular}{|c|c|c|c|c|c|}
\hline $\begin{array}{l}\text { PNAEP- } b- \\
\text { PDMAEMA }\end{array}$ & $\begin{array}{l}\mathrm{pH}-\text { responsive } \\
\text { micelles }\end{array}$ & $\begin{array}{l}\text { direct dissolution at } \\
\text { acidic } \mathrm{pH} \text { followed by } \\
\text { self-assembly upon } \mathrm{pH} \\
\text { increase }\end{array}$ & $\mathrm{D}_{h} \sim 50-100 \mathrm{~nm}$ & disass. $\leq$ pH 3 ; ass. $\geq$ pH 10 & {$[22]$} \\
\hline PNMP- $b$-PMA & $\begin{array}{l}\text { micelles for } \mathrm{Au} \mathrm{NP} \\
\text { templating }\end{array}$ & $\begin{array}{l}\text { direct dissolution in } \\
\text { water }\end{array}$ & $\begin{array}{l}\mathrm{D}_{h} \sim 100 \mathrm{~nm}(\mathrm{pH} 4) \mathrm{D}_{h} \sim 200 \mathrm{~nm} \\
(\mathrm{pH} 2)\end{array}$ & $\begin{array}{l}\text { ass. }<\mathrm{pH} 5.3 \text {. } \\
\text { micellization temperatures } \sim 50 \text { - } \\
70^{\circ} \mathrm{C} \text {. }\end{array}$ & {$[24]$} \\
\hline PVCL- $b$-PVP & $\begin{array}{l}\text { thermo-responsive } \\
\text { micelles }\end{array}$ & $\begin{array}{l}\text { direct dissolution in } \\
\text { water }\end{array}$ & $\mathrm{D}_{h} \sim 100-260 \mathrm{~nm}$ & ass. $\mathrm{T}>42-46^{\circ} \mathrm{C}$. & {$[25]$} \\
\hline PVA- $b$-PVCL & $\begin{array}{l}\text { thermo-responsive } \\
\text { and reducible } \\
\text { nanogels }\end{array}$ & $\begin{array}{l}\text { direct dissolution in } \\
\text { water and crosslinking } \\
\text { with DPA }\end{array}$ & $\begin{array}{l}\mathrm{D}_{h} \sim 280-460 \mathrm{~nm} \text { (DLS) } \\
\mathrm{D}_{h} \sim 45-110 \mathrm{~nm} \text { (TEM) }\end{array}$ & $\begin{array}{l}\text { ass. } \mathrm{T}>36-42^{\circ} \mathrm{C} \text {. } \\
\text { nanogels stable upon dilution } \\
\text { disass. with } 10 \mathrm{mM} \text { DTT after } \\
\text { 24h. }\end{array}$ & {$[28]$} \\
\hline PVA- $b$-PAA & $\begin{array}{l}\mathrm{pH}-\text { responsive } \\
\text { micelles and PIC } \\
\text { micelles }\end{array}$ & $\begin{array}{l}\text { direct dissolution in } \\
\text { water (micelles), mixing } \\
\text { with P2MVP- } b \text {-PEO } \\
\text { aqueous solutions (PIC } \\
\text { micelles) }\end{array}$ & $\begin{array}{l}\mathrm{D}_{h} \sim 200 \mathrm{~nm} \text { (micelles) } \\
\mathrm{D}_{h} \sim 30-40 \mathrm{~nm} \text { (PIC micelles) }\end{array}$ & ass. $\mathrm{pH}<3$ (micelles). & $\begin{array}{l}{[30,3} \\
1]\end{array}$ \\
\hline PCEtOx- $b$-PiPrOx & $\begin{array}{l}\mathrm{pH}-\& \text { thermo- } \\
\text { responsive micelles } \\
\& \text { vesicles }\end{array}$ & $\begin{array}{l}\text { direct dissolution in } \\
\text { water }(0.5 \mathrm{~g} / \mathrm{L})\end{array}$ & $\mathrm{D}_{h} \sim 50-230 \mathrm{~nm}$ & $\begin{array}{l}\text { ass. } 3.5 \leq \mathrm{pH} \leq 5.2 \text { at } 60^{\circ} \mathrm{C} \text {. } \\
\text { ass. } \mathrm{T} \geq 60^{\circ} \mathrm{C} \text {. }\end{array}$ & {$[35]$} \\
\hline PAA- $b$-PDHA & $\begin{array}{l}\text { loose } \\
\text { nanoaggregates }\end{array}$ & $\begin{array}{l}\text { direct dissolution in } \\
\text { water }\end{array}$ & $\begin{array}{l}\mathrm{D}_{h} \sim 220 \mathrm{~nm} / \xi \text { potential } \sim-5 \\
\mathrm{mV}(\mathrm{pH}<4)\end{array}$ & ass. $\mathrm{pH}<4$. & [39] \\
\hline
\end{tabular}




\section{Polysaccharide-based degradable DHBCs}

Polysaccharides are a broad class of naturally derived polymers (i.e. obtained from plants, animals or algae) that consist of monosaccharide units bound together by glycosidic linkages [44]. Polysaccharides display a linear or branched architecture and contain various functional groups such as carboxylic acid, amino and hydroxyl groups. These moieties are responsible for the hydrophilicity of many polysaccharides and offer numerous opportunities for chemical derivatization [45]. The molecular weight of polysaccharides may vary significantly (between hundreds and millions of Daltons), which further adds to the diversity of this polymer class [46]. In addition, owing to their native presence within the body, most polysaccharides have a very low toxicity and demonstrate good biocompatibility [47-50], while being enzymatically degradable down to their monomer or oligomer building blocks [51]. This unique combination of features explains their use as micellar systems for drug delivery which has been extensively reviewed $[52,53]$. Noteworthy, due to the chemical structure of polysaccharides most of their double hydrophilic copolymers (DHCs) have graft topologies rather than block topologies. Recent examples of such DHCs include chitosan-g-PEG [54-56], dextran grafted with poly((polyethylene glycol) methacrylate-co-aminoethyl methacrylate) [57] and alginic acid grafted with mPEG [58] that were all used to formulate drug loaded micelles. However, such graft copolymers, despite being double hydrophilic structures that offer interesting selfassembly behaviors are beyond the scope of this review that focuses on DHBCs and will not be further discussed. Examples of polysaccharide-based DHBCs where polysaccharides are used as functional and stimuli-responsive blocks (Table 1). A summary of the type of self-assemblies obtained with these copolymers and their characteristics is provided in Table 3.

Chitosan is a polysaccharide that has been widely used in DHCs but more scarcely in DHBCs. Although chitosan is insoluble in water at physiological $\mathrm{pH}$ and other common solvents because 
of its strong intra-molecular hydrogen bonding, its copolymerization with PEG or other hydrophilic polymers is known to disrupt the intra-molecular hydrogen bonding of chitosan, thus allowing its water solubilization. For this reason, and despite the fact that chitosan cannot be considered as a well solvated block on its own, the following structures can be considered as double hydrophilic structures. Ganji et al. reported on the synthesis of a chitosan-PEG DHBC (Figure 2 1) to be used as a thermosensitive gel. In a first step, the glycosidic bonds of the chitosan main chain were degraded with potassium persulfate to produce oligo-chitosan with a terminal carbonyl group at one scission end and a free radical at the other scission end. Then, the chain end with the free radical was reacted with acryloyl end-capped PEG (APEG, Mw= $2.10^{3} \mathrm{~g} \cdot \mathrm{mol}^{-1}$ ) giving rise to a diblock-like copolymer structure. The molar ratio of PEG/chitosan within the copolymer could be varied between 0.06 and 0.1 depending on the potassium persulfate concentration used to degrade chitosan. However, the MW of the chitosan segment was not really controlled, and it was also not clearly stated whether one or several acryloyl PEG chains can grow from the chitosan-end radical which may lead to chitosan- $b$-PEG or chitosan$b$-P(APEG). A gelation time of ca. 10 min was observed at body temperature for concentrations as low as $2 \mathrm{w} / \mathrm{v} \%$, which confirmed that these chitosan-PEG DHBC could be used for biomedical application [59].

To yield similar DHBCs, Moussa et al. used fully N-deacetylated chitooligosaccharides with a 5-anhydro-D-mannofuranose at their reducing end (COSamf) to prepare various COS-based building blocks. COSamf with an average number of 22 repeating units of $(1 \rightarrow 4)$-linked units of 2-amino-2-deoxy- $\beta$-D-glucopyranose $(\mathrm{GlcN})$ were functionalized via reductive amination. In particular 4-(propargyloxy)aniline and adipic dihydrazide were selected to prepare alkyne or hydrazide functional COSamf and prepare 2 different COS- $b$-PEG diblock copolymers based on chain ends reactions. The first method used copper(I)-catalyzed azide alkyne cycloaddition (CuAAC) reaction between the alkyne-terminated COS block and a commercial mPEG-azide 
$(\mathrm{Mn}=2000 \mathrm{~g} / \mathrm{mol}$ ) to yield COS- $b$-PEG with $\mathrm{Mn}=6520 \mathrm{~g} / \mathrm{mol}$ and $Đ=1.26$ (Figure 2 2). To get rid of the copper catalyst that may contaminate this first DHBC, the second strategy was based on the hydrazide condensation reaction between the hydrazide terminated COS block and a commercial mPEG-NHS ester $(\mathrm{Mn}=2000 \mathrm{~g} / \mathrm{mol})$ to yield COS- $b$-PEG with $\mathrm{Mn}=6330 \mathrm{~g} / \mathrm{mol}$ and $\mathrm{Đ}=1.15$ (Figure 2 3). These COS- $b$-PEG DHBCs are foreseen to serve as cationic nanocarriers for the delivery of drugs [60].
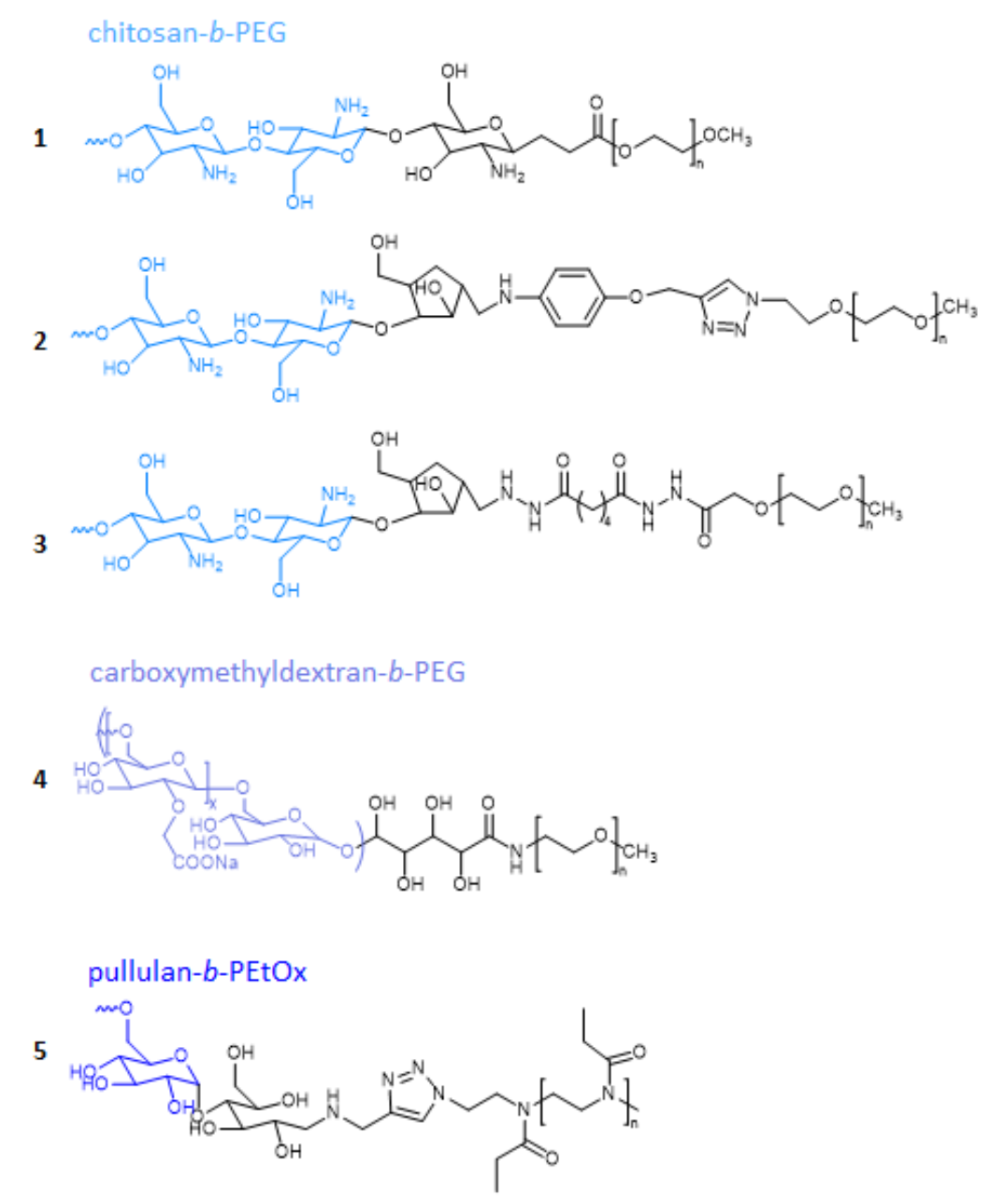

Figure 2. Examples of degradable hydrophilic block copolymers based on polysaccharides.

Dextran is another example of a polysaccharide found in DHBCs. Winnik et al. synthesized various block copolymers of dextran $(\mathrm{Mw}=8.3 \mathrm{k}$ or $14.7 \mathrm{k})$ and $\mathrm{PEG}-\mathrm{NH}_{2}(\mathrm{Mw}=3 \mathrm{k}$ or $7 \mathrm{k})$ via the specific oxidation of the dextran terminal aldehyde group and the covalent linkage of PEG$\mathrm{NH}_{2}$ via a lactone aminolysis reaction. Conversion of the neutral diblock copolymers into 
polyanions was achieved by carboxymethylation of the dextran block via side chain modification of dextran with chloroacetic acid, leading to carboxymethyldextran-PEG (CMD$b$-PEG) block copolymers (Figure 24 ). The properties of CMD- $b$-PEG in aqueous solutions were analyzed by static and dynamic light scattering (DLS) showing a pH sensitive assembly [61]. In follow up studies, the authors evaluated the ability of (CMD)- $b$-PEG to encapsulate different drugs. The micellization was evaluated as a function of i) the ionic charge density or degree of substitution (DS) of the dextran block with carboxymethyl moieties and ii) the molar ratio of positive charges provided by the drug to negative charges provided by CMD- $b$-PEG. PIC micelles were formed with the cationic and water soluble diminazene diaceturate (DIM), an API used as antiparasitic agent, and CMD- $b$-PEG with various DS. Micelles with a charge ratio positive/negative $=2$ had a DL ranging from 40 to $65 \mathrm{wt} \%$ with a hydrodynamic radius $(\mathrm{R} h)$ ranging from 36 to $50 \mathrm{~nm}$, depending on the MW and the DS of the CMD- $b$-PEG. The critical association concentration (CAC) was in the order of $15-50 \mathrm{mg} / \mathrm{L}$ for DIM/CMD- $b$-PEG with DS > $60 \%$, and $100 \mathrm{mg} / \mathrm{L}$ for DIM/CMD- $b$-PEG with DS 30 \%. Finally, PIC micelles with high DS and charge ratio = 2 allowed for a prolonged release of DIM in vitro compared with a solution of free drug [62]. In another application by the same group, the CMD- $b$-PEG was used to form PIC micelles with minocycline hydrochloride (MH), a semisynthetic tetracycline antibiotic with promising neuroprotective properties for the treatment of neuroinflammatory diseases. PIC micelles with $\mathrm{R} h$ of $100 \mathrm{~nm}$ and $50 \mathrm{wt} \%$ loading of $\mathrm{MH}$ were obtained. The MH loaded PIC micelles showed a sustained release of drug from the micelle at physiological $\mathrm{pH}$, thereby allowing to decrease inflammation in the murine microglia (N9) [63]. Lastly, CMD- $b$-PEG copolymers hydrophobized by n-dodecyl groups were used to encapsulate two aminoglycosides: paromomycin and neomycin at DL up to $50 \mathrm{wt} \%$. PIC micelles were stable under physiological conditions ( $\mathrm{pH} 7.4,150 \mathrm{mM} \mathrm{NaCl})$ in contrast with micelles formed by the unmodified CMD- $b$-PEG and exhibited reduced sizes (around $50 \mathrm{~nm}$ ) compared to the 
non-hydrophobized CMD- $b$-PEG (sizes in the range 75 to $100 \mathrm{~nm}$ ). The minimal inhibitory concentration of the aminoglycosides encapsulated in PIC micelles was not altered as indicated by their ability to kill E.Coli in culture [64].

Brosnan et al. synthesized dextran and pullulan based DHBCs, namely dextran- $b$-poly (ethylene oxide) (Dex- $b$-PEO), pullulan- $b$-PEO (Pul- $b$-PEO), and dextran- $b$-poly(sarcosine) (Dex-b-PSar). The synthesis route involved reaction of one polysaccharide terminus, existing as an aldehyde group in the equilibrium state, with a hydroxy amine end group of monofunctionalized PEO or PSar, yielding a hydrolytically stable oxime bond between both polymer blocks. Each block had a MW of ca. $20 \mathrm{k}$ yielding DHBCs with MW of ca. $40 \mathrm{k}$. A direct dissolution at low concentrations $(0.1,0.5$, and $1.0 \mathrm{wt} \%)$ led after 7 days to the formation of self-assembled polymer vesicles with $\mathrm{R} h$ in the range of $250 \mathrm{~nm}$ to $700 \mathrm{~nm}$ for the lowest and the highest concentrations, respectively. At higher concentrations, above $10 \mathrm{wt} \%$, selfassembly yielded giant polymer vesicles, referred as "aquanelles" with sizes between 2 and 20 $\mu \mathrm{m}$ (Figure 3). These aquanelles' solutions were stable over 7 days and due to their water permeability, the authors envisioned that they could be well suited for use as artificial cells [65].

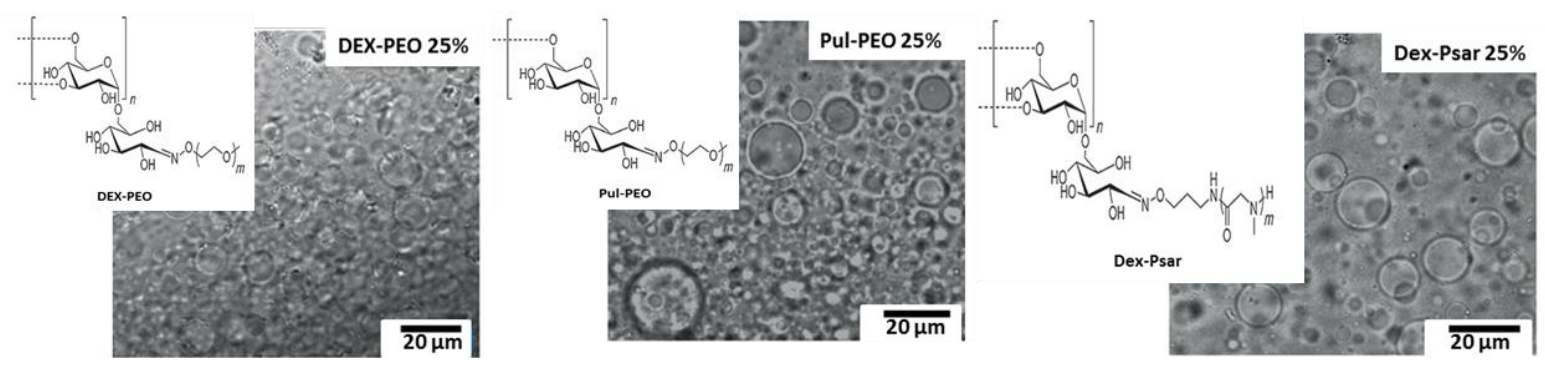

Figure 3. Optical microscopy images of the giant double hydrophilic polymer vesicles referred to as "aquanelles" prepared from Dex- $b$-PEO, Pul- $b$-PEO and Dex- $b$-PSar at $25 \mathrm{wt} \%$ (adapted with permission from [65]). 
The self-assembly of pullulan- $b$-poly(2-ethyl-2-oxazoline) (Pull- $b$-PEtOx) was studied by Willersin et al. The DHBC (Figure 25 ) was synthesized from a pullulan-alkyne (8-38 kg mol${ }^{1}$ ) and a biocompatible azido-PEtOx $\left(22 \mathrm{~kg} \mathrm{~mol}^{-1}\right)$ by a CuAAC conjugation. The MW of the Pull block was varied to study its impact on the self-assembly behavior. Sizes between 300 and $500 \mathrm{~nm}$ were measured by DLS and static light scattering (SLS) in dilute aqueous solution (0.1$1.0 \mathrm{wt} \%$ ) with an optimum ratio of 0.4/0.6 (Pull/PEtOx) for the assembly of copolymers in water. Larger particulate structures with sizes around 1 to $2 \mu \mathrm{m}$ were observed by optical microscopy at a higher concentration (20 wt\%) [66]. 
Table 3: Characteristics of the self-assemblies obtained with polysaccharide-based degradable double hydrophilic block copolymers.

\begin{tabular}{|c|c|c|c|c|c|}
\hline \multirow{2}{*}{ DHBC } & \multicolumn{3}{|c|}{ Self-assemblies } & \multirow{2}{*}{ Stability / Degradation ${ }^{a}$} & \multirow[t]{2}{*}{ Ref. } \\
\hline & Type & Preparation & Characteristics $^{\mathbf{a}}$ & & \\
\hline PEG- $b$-chitosan & $\begin{array}{l}\text { Thermosensitive } \\
\text { gel }\end{array}$ & $\begin{array}{l}\text { dissolution of DHBC in } \\
\text { PBS at } 2 \text { or } 3 \mathrm{wt} \%\end{array}$ & gelation time 6-11 min & sol $<35-40^{\circ} \mathrm{C}<$ gel. & [59] \\
\hline \multirow[b]{2}{*}{$\begin{array}{l}\text { PEG- } b \text { - } \\
\text { carboxymethyldextran }\end{array}$} & $\begin{array}{l}\text { DIM-loaded PIC } \\
\text { micelles }\end{array}$ & $\begin{array}{l}\text { DIM : mixing of DHBC } \\
\text { and DIM Tris buffer } \\
\text { solutions (pH 5.3, R = } \\
\text { 2), }\end{array}$ & $\begin{array}{l}\text { DIM : CAC 0.014-0.095 g/L / } \\
\mathrm{D}_{h} \sim 70-100 \mathrm{~nm} / \xi \text { potential - } \\
3.4 \mathrm{mV} / \mathrm{DL} \sim 40-65 \%\end{array}$ & $\begin{array}{l}\text { dissa. } \geq 0.2 \mathrm{M} \mathrm{NaCl} \\
\text { stable from } \mathrm{pH} 4 \text { to } 1.1 \\
25 \% \text { size increase over 2- month } \\
\text { storage in Tris (pH 5.3). }\end{array}$ & \multirow[b]{2}{*}{$\begin{array}{l}{[61-} \\
63]\end{array}$} \\
\hline & $\begin{array}{l}\text { MH-loaded PIC } \\
\text { micelles }\end{array}$ & $\begin{array}{l}\mathrm{MH}: \text { mixing of DHBC } \\
\text { and } \mathrm{MH} / \mathrm{CaCl}_{2} \text { Tris- } \\
\text { buffer solutions ( } \mathrm{pH} 7.4 \text {, } \\
\mathrm{R}=1 \text { ) }\end{array}$ & $\begin{array}{l}\mathrm{MH}: \mathrm{D}_{h} \sim 200 \mathrm{~nm}(\mathrm{MH}) / \mathrm{DL} \sim \\
50 \%\end{array}$ & $\begin{array}{l}\text { stability over 1-month storage } \\
\text { in Tris ( } \mathrm{pH} 7.4) \text {. }\end{array}$ & \\
\hline $\begin{array}{l}\text { PEG- } b \text {-(n-dodecyl)- } \\
\text { carboxymethyldextran }\end{array}$ & $\begin{array}{l}\text { PAR-loaded PIC } \\
\text { micelles } \\
\text { NEO-loaded PIC } \\
\text { micelles }\end{array}$ & $\begin{array}{l}\text { mixing of DHBC and } \\
\text { PAR or NEO PBS } \\
\text { solutions (pH 7.4, R = } \\
2.5 \text { ) }\end{array}$ & $\begin{array}{l}\text { PAR : CAC } 0.125 \mathrm{~g} / \mathrm{L} / \mathrm{D}_{h^{\sim}} \\
100 \mathrm{~nm} / \mathrm{DL} \sim 50 \% \\
\mathrm{NEO}: \mathrm{CAC} 0.06 \mathrm{~g} / \mathrm{L} / \mathrm{D}_{h^{\sim}} \sim 80- \\
120 \mathrm{~nm} / \mathrm{DL} \sim 50 \%\end{array}$ & $\begin{array}{l}\text { PAR : stable at } 100 \mathrm{mM} \mathrm{NaCl} \text {. } \\
\text { NEO : stable at } 200 \mathrm{mM} \mathrm{NaCl} \\
\text { and stability > } 3 \text { months at } \\
150 \mathrm{mM} \mathrm{NaCl} \text { and } \mathrm{pH} 7.4 \text {. }\end{array}$ & [64] \\
\hline $\begin{array}{l}\text { PEO- } b \text {-dextran } \\
\text { PEO- } b \text {-pullulan } \\
\text { PSar- } b \text {-dextran }\end{array}$ & giant vesicles & $\begin{array}{l}\text { direct dissolution in } \\
\text { water }\end{array}$ & $\begin{array}{l}\mathrm{R} h \sim 250 \text { to } 700 \mathrm{~nm} \text { for } 0.1 \text { to } \\
1.0 \mathrm{wt} \% / \mathrm{R} h \sim 2 \text { to } 20 \mu \mathrm{m} \text { for } \\
10 \text { to } 25 \mathrm{wt} \%\end{array}$ & stability > 7 days. & [65] \\
\hline PEtOx- $b$-pullulan & Nanoparticles & $\begin{array}{l}\text { direct dissolution in } \\
\text { water }\end{array}$ & $\begin{array}{l}\mathrm{D}_{h} \sim 320-500 \mathrm{~nm}(\text { minor } \\
\left.\text { population with } \mathrm{D}_{h} \sim 10-15 \mathrm{~nm}\right)\end{array}$ & $\begin{array}{l}\text { stability for } \mathrm{pH} 5 \text { to } 9 \text { and } 2 \mathrm{M} \\
\mathrm{NaCl} \text {. }\end{array}$ & [66] \\
\hline
\end{tabular}




\section{Polypeptide-based degradable DHBCs}

Polypeptides have an inherent biocompatibility (with the exception of high concentrations and polycationic polypeptides with a high MW) [67] and possess a simple polymeric structure. They can form secondary structure motifs that can mimic protein behavior and introduce additional intermolecular forces such as hydrogen bonding [68,69]. The incorporation of polypeptide sequences, such as pH-responsive poly(L-lysine) (PLL) and poly(glutamic acid) (PGlu), into DHBCs can endow them with additional structural versatility, tunable spatial arrangement of chain segments within self-assembled nanostructures, enhanced biocompatibility and broader applications in the field of biomedicines.

In this part we will discuss recent examples of DHBCs containing polypeptides as the functional block (Table 1). A summary of the type of self-assemblies obtained with these DHBCs and their characteristics is provided in Table 4.

Wu et al. reported on the synthesis of double hydrophilic PEtOx- $b$-PSar copolymers via a onepot two-step approach (Figure 4). PEtOx-ammonium phosphate was first obtained by polymerization of 2-ethyl-2-oxazoline in the presence of the mild brönsted acid diphenyl phosphate (DPP), and was further used as macroinitiator for the ROP of sarcosine Ncarboxyanhydride (Sar-NCA) [70]. 

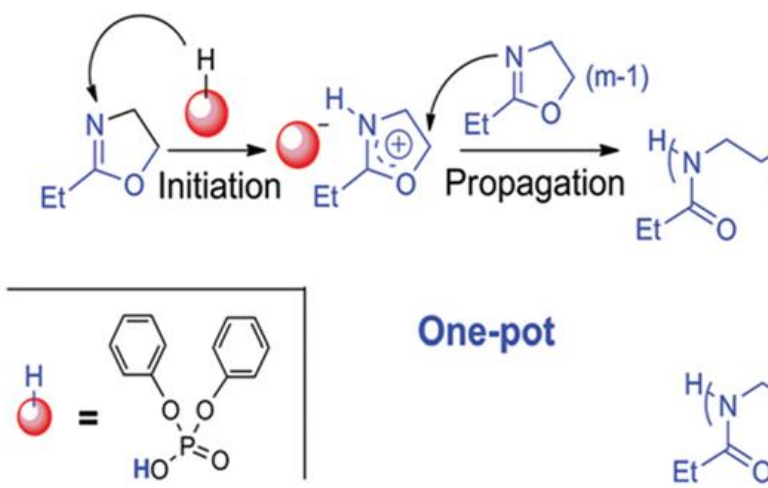

One-pot


Figure 1. One-pot synthesis of PEtOx- $b$-PSar diblock copolymers [70].

Salmanpour et al. synthesized poly(2-ethyl-2-oxazoline)-b-poly(benzyl-L-glutamate) (PEtOXb-PbGlu) via cationic ROP of 2-ethyl-2-oxazoline, subsequent amine functionalization of PEtOX using 1-Boc-piperazine and finally $\mathrm{N}$-carboxyanhydride polymerization of benzyl-Lglutamate [71]. PEtOX- $b$-poly(L-glutamic acid) (PEtOX- $b$-PGlu) DHBCs were obtained after removal of the protecting benzyl groups via hydrolysis. In contrast with PEtOX- $b$-PbGlu copolymers, which formed micelles in aqueous solution, PEtOX- $b$-PGlu was freely soluble in water as demonstrated with DLS. Chemical conjugation of the chemotherapeutic agent SN38 to the carboxylic acid groups of the PGlu block via carbodiimide mediated esterification resulted in PEtOX-b-PGlu-SN38 conjugates [72]. Thanks to the hydrophobicity of SN38 these polymer-drug conjugates self-assembled in aqueous solution into spherical particles of $90 \mathrm{~nm}$. In vitro experiments with colorectal carcinoma cells demonstrated a higher cellular uptake and a higher cytotoxicity for polymer-conjugated SN38 than for free drug. However, the nonspecificity of the hydrolysis reaction may result in premature drug release and side effects.

Also, two sets of double hydrophilic block copolymers with PEG and either poly(L-aspartic acid) (PAsp) or poly(L-glutamic acid) (PGlu) were successfully synthesized by Kasparova et al. via ring opening polymerization of their respective protected $\mathrm{N}$-carboxyanhydride monomers using $\alpha$-methoxy- $\omega$-amino[poly(ethylene glycol)] (PEG-NH${ }_{2}$ ) as macroinitiator 
[73]. The resulting DHBCs were applied in the crystallization of $\mathrm{CaCO}_{3}$ and $\mathrm{BaSO}_{4}$. All $\mathrm{DHBCs}$ with a minimum of 10 amino acids were shown to be effective in modifying crystal growth and promoting the formation of different crystal superstructures up to concentrations of $0.05 \mathrm{~g} / \mathrm{l}$, such as well-defined ball-shaped, extension and dumbbell particles between 2 and $10 \mu \mathrm{m}$ in size. $\mathrm{CaCO}_{3}$ particles with prolonged stability of at least one year were obtained via an aggregation of metastable vaterite nanoparticles.

Kataoka's group developed a method based on charge-conversional PIC micelles, for the efficient delivery of protein into cytoplasm by a cationic DHBC composed of PEG and a cationic segment based on PAsp bearing a N-(2-aminoethyl)-2-aminoethyl group (PAsp(DET)) (Figure 5, middle row), that acts as a buffering moiety inducing endosomal escape with minimal cytotoxicity. This DHBC was associated with protein derivatives. They selected equine heart cytochrome c $(\mathrm{CytC} ; \mathrm{Mw}=12384 \mathrm{Da})$, an essential protein in the electron transfer of the mitochondria, as a model protein. CytC was modified with citraconic anhydride or cis-aconitic anhydride to increase the charge density and form anionic $\mathrm{CytC}$ derivatives, namely $\mathrm{CytC}-\mathrm{Cit}$ and CytC-Aco (Figure 5, top row). DLS measurements showed the PIC micelles to have a unimodal size distribution with diameters of about $50 \mathrm{~nm}$ and PDI values of about 0.05 , also at physiological salt concentration $(150 \mathrm{~mm} \mathrm{NaCl})$. Spherical PIC micelles were formed at a N/C (amine/carboxylate) ratio of 2 . Over $50 \%$ of CytC-Cit was released from the PIC micelles within 4 hours at $\mathrm{pH} 5.5$, whereas only $10 \%$ was released after 8 hours at $\mathrm{pH} 7.4$. Experiments with CytC-Aco showed similar release profiles but with a slower release. The intracellular distribution of the CytC derivatives after incubation for $24 \mathrm{~h}$ with $\mathrm{HuH}-7$ hepatocyte-derived carcinoma cells was investigated (Figure 5, bottom row). The charge-conversional PIC micelles containing CytC-Aco or CytC-Cit showed an efficient release of CytC. It was assumed that the 
polymer released from the PIC micelles could come into direct contact with the endosomal membrane to induce the efficient escape of the CytC into the cytoplasm [74].
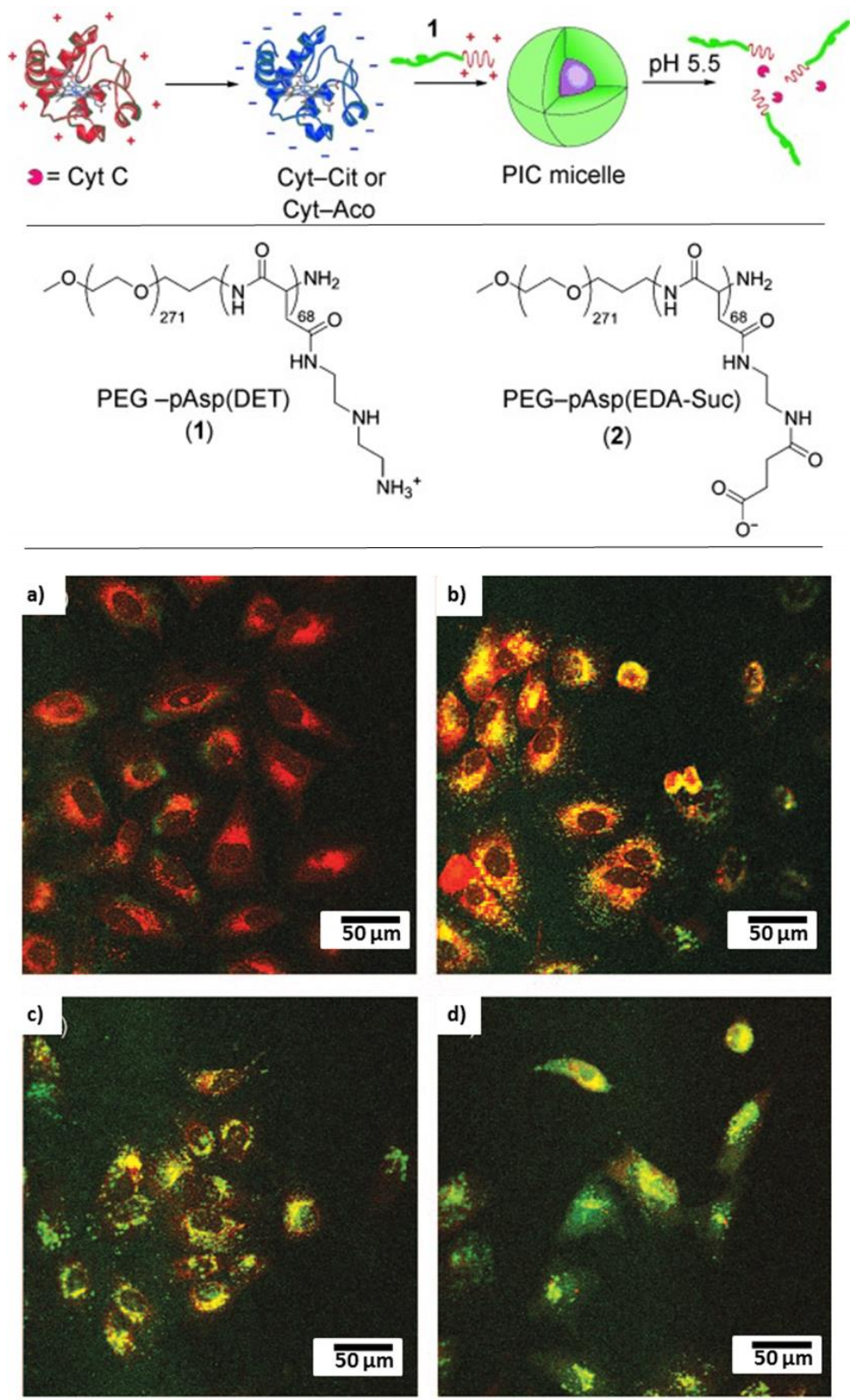

Figure 2. Top row: schematic representation showing the preparation of charge-conversional PIC micelles containing CytC derivatives and PEG-pAsp(DET). Middle row: chemical structures of PEG-pAsp(DET) and of PEG-pAsp(EDA-Suc). Bottom row: CLSM images of HuH-7 delivered by a) free native CytC control, b) succinyl CytC PIC non-charge conversional anionic derivative controls, c) Cyt-Aco PIC micelles, and d) Cyt-Cit PIC micelles after $24 \mathrm{~h}$ transfection. Each CytC derivative was labeled with Alexa Fluor 488 (green). The late endosome and lysosome were stained with Lyso-Tracker Red (red). CytC in the endosome was detected as yellow prior release and as green after release (adapted with permission from [74]). 
The same group synthesized a similar DHBC PEG-SS-P(Asp(DET)) containing a biocleavable disulfide. The cationic DHBC was complexed with plasmid DNA (pDNA) yielding polyplex micelles with a size around $80 \mathrm{~nm}$, which are stabilized by the hydrophilic PEG blocks. In contrast, aggregation was rapidly observed upon addition of $10 \mathrm{mM}$ dithiothreitol (DTT) as a consequence of the disulfide reduction and PEG cleavage from the micelles. The gene transfection efficiency of the PEG-SS-P(Asp(DET)) micelles was higher than the one of PEG$\mathrm{P}(\mathrm{Asp}(\mathrm{DET}))$ micelles as a result of a much more effective endosomal escape thanks to the detachment of the PEG in the endosome [75].

Li et al. synthesized a mPEG- $b$-PGlu derivative bearing mercaptosuccinic acid (MSA) methoxypoly(ethylene glycol)- $b$-poly( $\gamma$-propargyl-L-glutamate-g-mercaptosuccinic acid) (mPEG-b-(PPLG-g-MSA)) (Figure 6 1) by combining the ROP of a clickable propargyl-GluNCA and the subsequent thiol-yne photoaddition of MSA. The self-assembly of the anionic polymer and cationic DOX.HCl in aqueous medium led to the formation of $\mathrm{pH}$-responsive polymersomes with a size of $20 \mathrm{~nm}$ and $99 \mathrm{wt} \%$ EE. CLSM (Confocal Laser scanning microscope) and FACS (Flow cytometry analysis) studies confirmed that the FITC-labeled drug delivery polymersomes were taken up by A549 cells via endocytosis. Biodistribution studies in nude mice bearing A549 tumors showed less uptake of the polymersomes by the liver and kidneys compared to the free DOX.HCl, as well as a stronger fluorescence in the tumor (Figure 6 2). These results indicate that polymersomes loaded with DOX.HCl are able to modify the biodistribution of the drug and thereby reduce its systemic toxicity [76]. 
1)

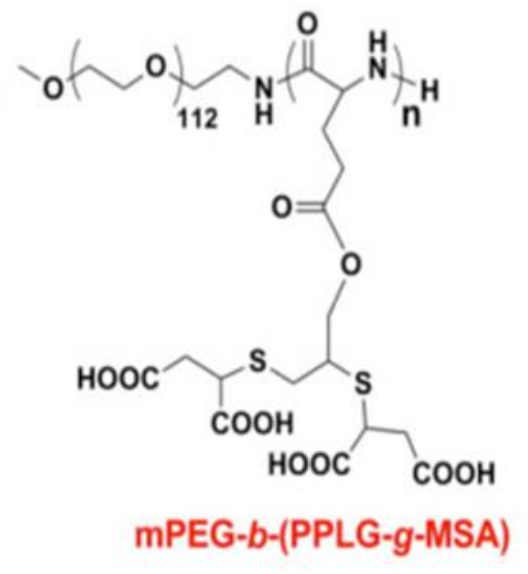

2)

Heart Liver Spleen Lung Kidney Tumor
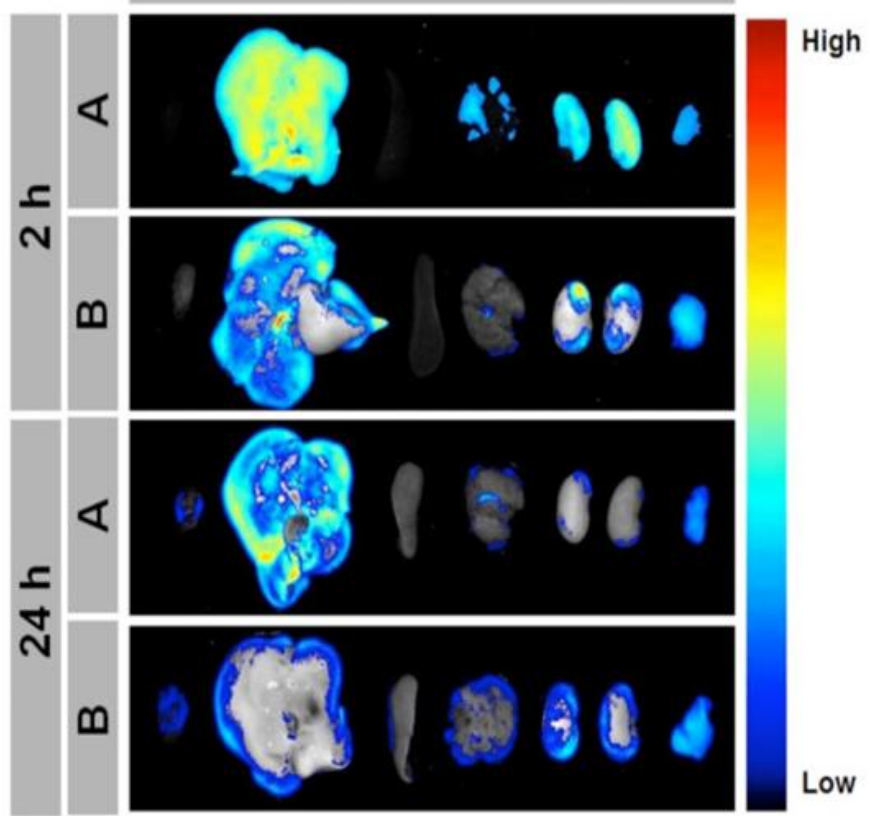

Figure 3. 1) Structure of mPEG-b-(PPLG-g-MSA) 2) Ex vivo DOX.HCl fluorescence images showing the drug bio-distribution of A) free DOX.HCl and B) mPEG-b-(PPLG-g-MSA)-DOX $\mathrm{HCl}$ polymersomes in nude mice bearing A549 tumors at 2 and $24 \mathrm{~h}$ post-injection (adapted with permission from [76]).

Several studies report on the preparation of polypeptide-based PIC micelles for cancer treatment via photodynamic therapy, using either PEG- $b$-PAsp or PEG- $b$-PLL as DHBCs, depending on the nature of the photosensitizers [77,78]. Photodynamic therapy (PDT) involves systemic administration of porphyrin or phthalocyanine-based photosensitizers (PSs), followed by local photoirradiation of solid tumors with a specific wavelength light. As an example, PIC micelles formed via the electrostatic interactions between anionic dendrimer phthalocyanine zinc (DPcZn) and PEG- $b$-PLL (DPcZn/m) were prepared for use as an effective photosensitizer for photodynamic therapy at $650 \mathrm{~nm}$. DPcZn/m PIC micelles had a size around $50 \mathrm{~nm}$, which is suitable for intravenous administration. DPcZn and DPcZn/m exhibited an effective uptake of dissolved oxygen to generate reactive oxygen species ROS under light irradiation with an increase in photocytotoxicity as a function of irradiation time. However, after 60 minutes, $\mathrm{DPcZn} / \mathrm{m}$ exhibited almost 100 times higher photocytotoxicity than free DPcZn, along with a 
4 times higher cellular uptake for DPcZn/m due to the charge neutralization of the DPcZn by the micelles [79].

PEG- $b$-PLL DHBCs have also been proposed to yield MRI macromolecular contrast agents. Yokoyama et al. substituted ca. $50 \%$ of the lysine moieties of $\mathrm{PEG}_{118}-b$-PLL 34 with DOTA mono(N-hydroxysuccinimide ester) before complexation with $\mathrm{Gd}^{3+}$ ions. The resulting DHBC with 7 DOTA/Gd moieties formed micelles with a size of $43 \mathrm{~nm}$ and larger aggregates of 225 $\mathrm{nm}$ with a zeta potential of $-9.55 \mathrm{mV}$. The Gd-loaded micelles were able to circulate for $48 \mathrm{~h}$ in colon 26-bearing CDF1 female mice blood stream with a significant accumulation in tumor tissues. This result demonstrates the applicability of this DHBC as a diagnostic tool, which was confirmed by a subsequent study using them for magnetic resonance lymphography [80,81].

In another application, PIC micelles were formed between the cationic antimicrobial peptide MSI-78 and the anionic PEG- $b$-PGlu DHBC to develop antimicrobial agents. The mean diameters of the spherical PIC micelles decreased with an increase in the length of the negatively charged PGlu block with sizes ranging from 80 to $120 \mathrm{~nm}$, as observed by TEM. A sustained release of FITC-labeled MSI-78 was obtained from the PIC micelles for more than 40 hours. Importantly, these PIC micelles greatly decreased the hemolytic toxicity of MSI-78 to human red blood cells, without influencing its antimicrobial activity as shown with maintained MIC (minimum inhibitory concentration) values against Gram-negative E. coli and Gram-positive B. subtilis and S. aureus [82]. 
Table 4: Characteristics of the self-assemblies obtained with polypeptide-based degradable double hydrophilic block copolymers.

\begin{tabular}{|c|c|c|c|c|c|}
\hline DHBC & \multicolumn{3}{|c|}{ Self-assemblies } & Stability / Degradation ${ }^{a}$ & Ref. \\
\hline PEtOx- $b$-PSar & & & not evaluated & & [70] \\
\hline PEtOx- $b$-PGlu & $\begin{array}{l}\text { SN38-conjugated } \\
\text { micelles }\end{array}$ & $\begin{array}{l}\text { direct dissolution in } \\
\text { water, } 3 \text { days incubation }\end{array}$ & $\begin{array}{l}17 \mathrm{wt} \% \mathrm{SN} 38 \text { conjugated } \\
\mathrm{CMC}=0.02 \mathrm{mg} / \mathrm{mL} / \mathrm{D}_{h} \sim 91 \\
\mathrm{~nm} / \xi \text { potential } 2.6 \mathrm{mV}\end{array}$ & not evaluated. & $\begin{array}{l}{[71,7} \\
2]\end{array}$ \\
\hline $\begin{array}{l}\text { PEG- } b \text {-PGlu } \\
\text { and PEG- } b \text {-PAsp }\end{array}$ & $\begin{array}{l}\text { templating of } \\
\mathrm{CaCO}_{3} \text { and } \mathrm{BaSO}_{4}\end{array}$ & $\begin{array}{l}\text { Double-Jet method } \\
(\mathrm{DJM}): \text { slow injection } \\
\text { of }\left(\mathrm{Na}_{2} \mathrm{CO}_{3} \text { and } \mathrm{CaCl}_{2}\right) \\
\text { or }\left(\mathrm{Na}_{2} \mathrm{SO}_{4} \text { and } \mathrm{BaCl}_{2}\right) \\
\text { solutions in DHBC } \\
\text { solution }\end{array}$ & $\begin{array}{l}\mathrm{CaCO}_{3}: 15-20 \mathrm{~nm} \text { vaterite } \\
\text { particles at } 0.05 \mathrm{~g} / \mathrm{L}<\mathrm{DHBC} \\
\leq 1 \mathrm{~g} / \mathrm{L} \\
\mathrm{BaSO}_{4}: 2-3 \mu \mathrm{m} \text { particles at } 0.5 \\
\mathrm{~g} / \mathrm{L}<\mathrm{DHBC} \leq 5 \mathrm{~g} / \mathrm{L}\end{array}$ & $\begin{array}{l}\text { vaterite metastable form } \\
\text { maintained over } 1 \text { year. }\end{array}$ & [73] \\
\hline PEG- $b$-PAspED & $\begin{array}{l}\text { CytC-loaded PIC } \\
\text { micelles }\end{array}$ & $\begin{array}{l}\text { Mixing of CytC and } \\
\text { DHBC water solutions } \\
(\mathrm{R}=2) \text {, addition of } \\
\text { acetate or phosphate } \\
\text { buffer to reach } 150 \mathrm{mM} \\
\mathrm{NaCl}\end{array}$ & $\mathrm{D}_{h} \sim 50 \mathrm{~nm}$ & $\begin{array}{l}50 \% \text { CytC release at } \mathrm{pH} 5.5 \\
\text { vs. } 10 \% \text { at } \mathrm{pH} 7.4 \text { after } 4 \mathrm{~h} .\end{array}$ & [74] \\
\hline mPEG- $b$-PPLG-MSA & $\begin{array}{l}\text { DOX-loaded } \\
\text { polymersomes }\end{array}$ & $\begin{array}{l}\text { DHBC aqueous solution } \\
\text { at } \mathrm{pH} 7.4 \text {. Overnight } \\
\text { stirring, } 24 \mathrm{~h} \text { dialysis } v s \text {. } \\
\text { water }\end{array}$ & EE 99\% / DL 16,5\% & $\begin{array}{l}63 \% \text { DOX release at } \mathrm{pH} 5.5 \\
\text { vs. } 27 \% \text { at } \mathrm{pH} 7.4 \text { after } 60 \mathrm{~h} .\end{array}$ & [76] \\
\hline PEG- $b$-PLL & $\begin{array}{l}\text { DPcZn-loaded PIC } \\
\text { micelles }\end{array}$ & $\begin{array}{l}\text { Mixing of DHBC and } \\
\text { DPcZn aqueous } \\
\mathrm{NaH}_{2} \mathrm{PO}_{4} \text { solutions ( } \\
=1, \mathrm{pH} 7.3)\end{array}$ & $\mathrm{D}_{h} \sim 50 \mathrm{~nm}$ & $\begin{array}{l}\text { stability of PIC micelles in } \\
10 \mathrm{mM} \text { PBS in the presence of } \\
10 \% \text { FBS. }\end{array}$ & [79] \\
\hline
\end{tabular}




\begin{tabular}{|c|c|c|c|c|}
\hline PEG- $b$-PLL & $\begin{array}{l}\mathrm{Gd}^{3+-} \text { loaded } \\
\text { micelles }\end{array}$ & $\begin{array}{l}\text { Dissolution of DHBC in } \\
150 \mathrm{mM} \mathrm{NaCl} \text { solution. }\end{array}$ & $\begin{array}{l}\mathrm{D}_{h} \sim 43 \& 225 \mathrm{~nm} / \xi \text { potential } \\
-9.55 \mathrm{mV}\end{array}$ & $\begin{array}{l}\text { stable in the presence of vaca } \\
\text { DOTA groups leading to } \\
\text { DOTA-DOTA interactions }\end{array}$ \\
\hline PEG- $b$-PGlu & $\begin{array}{l}\text { AMP-loaded PIC } \\
\text { micelles }\end{array}$ & $\begin{array}{l}\text { Mixing of DHBC and } \\
\text { AMP aqueous solutions } \\
(1: 1 \text { molar ratio), } \\
\text { dialysis } 6 \mathrm{~h} v s . \text { water }\end{array}$ & $\begin{array}{l}\mathrm{D}_{h} \sim 196-277 \mathrm{~nm} / \xi \text { potential - } \\
16 \text { to }-39 \mathrm{mV} / \mathrm{EE} \sim 75-88 \% \text { / } \\
\mathrm{DL} \sim 19-23 \%\end{array}$ & $\begin{array}{l}80 \% \text { release at } \mathrm{pH} 7.4 \text { after } \\
72 \mathrm{~h} .\end{array}$ \\
\hline
\end{tabular}

Abbreviations : AMP antimicrobial peptide ; ass. assembly ; CytC cytochrom C ; disass. disassembly ; DTT dithiothreitol ; DOX doxorubicin ; DPcZn dendrimer

phthalocyanine zinc ; FBS fetal bovine serum ; $\mathrm{Gd}^{3+}$ gadolinium ion ; PAsp poly(aspartic acid) ; PAspED poly(aspartic acid(ethylene diamine)) ; pDNA plasmid

DNA ;PEtOx, poly(2-ethyl-2-oxazoline) ; PGlu poly(L-glutamic acid) ; PLL poly(lysine) ; PPLG-MSA poly( $\gamma$-propargyl-L-glutamate- $g$-mercaptosuccinic acid) ; PSar poly(sarcosine) ; R charge ratio between positive and negative charges ; SN38 7-Ethyl-10-hydroxy camptothecin.

a ranges of provided values correspond to characteristics obtained as a function of the blocks' length of the used DHBCs and/or ratios of compounds. If not specified sizes correspond to the hydrodynamic diameters or radii measured by DLS. 


\section{Polyester-based degradable DHBCs and others miscellaneous synthetic blocks}

Polyesters are polymers that can be hydrolyzed in accordance with the thermodynamic reversibility of the esterification reaction. This feature, associated with a recognized biocompatibility for some of them, e.g. those derived from lactic acid (LA), glycolic acid (GA) or $\varepsilon$-caprolactone (CL), explain their wide success in many biomedical applications such as implantable devices, drug delivery systems or scaffolds for tissue engineering. However, polyesters are known for their intrinsic hydrophobicity [83]. The lack of structural diversity of polyesters appears as an important limitation in terms of functionality and physico-chemical properties. As a consequence, various methodologies to introduce functional groups onto polyester backbones have been reported [84-88], for example to poly( $\varepsilon$-caprolactone) (PCL) functionalized with hydrophilic groups such as hydroxyl [89], carboxyl [90,91], or amino groups [92]. DHBCs containing such functional polyesters as functional block will be discussed in this part (Table 1). A summary of the type of self-assemblies obtained with these DHBCs and their characteristics is provided in Table 5.

Liu et al. synthesized a family of aminated DHBCs in 5 steps via ROP of $\gamma$-(carbamic acid benzylester)- $\varepsilon$-caprolactone ( $\gamma \mathrm{CAB} \varepsilon \mathrm{CL})$ in bulk using $\mathrm{mPEG}$ as macro-initiator to yield, after deprotection, mPEG- $b$-PACL that can be candidates for $\mathrm{pH}$-sensitive drug delivery, especially for anionic hydrophilic drugs or genes (Figure 7 1). The authors studied the solution properties of the various DHBCs as a function of $\mathrm{pH}$ and PACL block length and highlighted by DLS the presence of unimers or aggregates with sizes ranging from 50 to $250 \mathrm{~nm}$ depending on the parameters previously cited [93].

By copolymerization of caprolactone (CL) and CL bearing reactive groups like chloro $\varepsilon$ caprolactone (ClCL) that can be derivatized after polymerization into an azido-PCL, 
Charoongchit et al. obtained a clickable triblock $\left(\mathrm{P}\left(\alpha-\mathrm{N}_{3}-\mathrm{CL}-\mathrm{co}-\mathrm{CL}\right)_{2}-\mathrm{PEG}\right.$ copolymer that was reacted with propargyltrimethyl ammonium iodide to yield the cationic (P( $\alpha$-TMA-CL-coCL) 2 -PEG bearing trimethyl ammonium (TMA) side groups (Figure 7 2). The surface charge of $\left(\mathrm{P}(\alpha-\mathrm{TMA}-\mathrm{CL}-\mathrm{co}-\mathrm{CL})_{2}-\mathrm{PEG}\right.$ particles was positive due to the grafted cationic ligand present on the surface of the particles. The authors compared the particle size for different contents of cationic ligand but with constant PCL chain length, and found that the particle size increased with increasing the mol\% of cationic ligand.[94] These cationic copolymers showed a capability to entrap enoxaparin, a low molecular weight heparin used in the treatment of deep vein thrombosis and pulmonary embolism [95], with 87\% EE and 8\% DL [94]. 
$\mathrm{CH}_{3} \mathrm{O} \mathrm{N}_{\mathrm{m}}$

1



3<smiles>COC(C)(C)COC(=O)CCCCCOc1ccccc1</smiles>

5

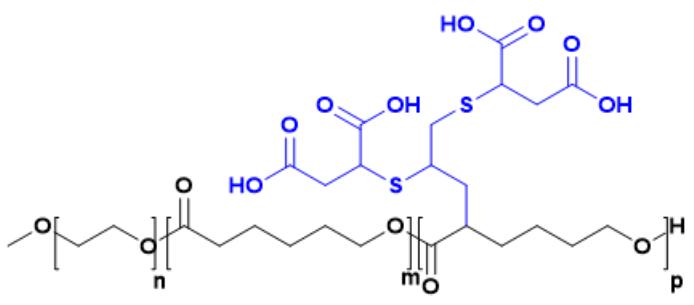

6<smiles>[R]OC(=O)CCCCC(CC(=O)O)OC(C)(C)C(=O)CNCCCO[Tl]</smiles>

$\mathrm{CH}_{3} \mathrm{O} \sim \mathrm{O}_{\mathrm{m}}^{\mathrm{II}} \mathrm{P}_{\mathrm{Na}}^{\mathrm{O}} \mathrm{O}_{\mathrm{Na}}$

9'



2

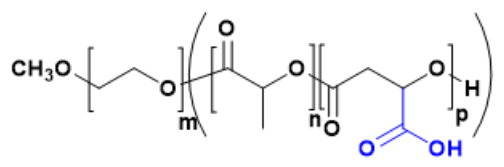

4

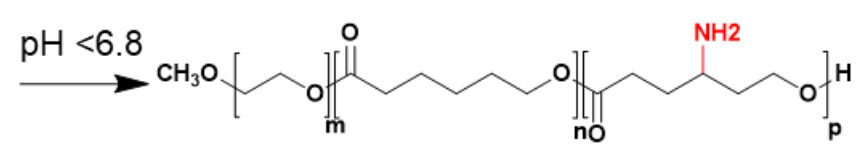

5

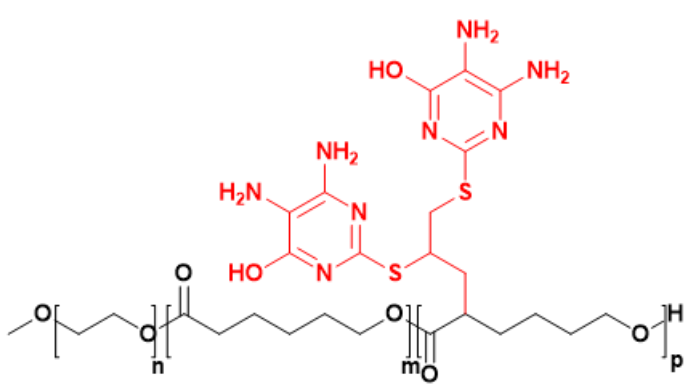

7
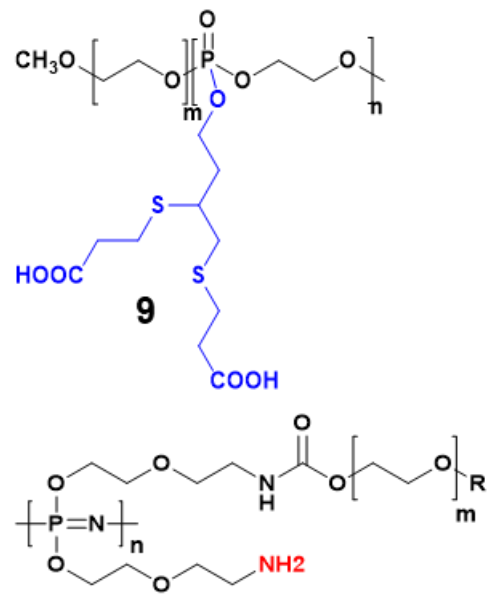

10

Figure 4. Degradable hydrophilic block copolymers based on polyester, polyphosphoester and polyphosphazene blocks. 
Gao et al. reported on the synthesis of PEG- $b$-poly( $\beta$-aminoester)-1-(3-aminopropyl)imidazole (PEG-PAE-API) by a Michael-type step polymerization between monoacrylated PEG, 1,6hexanediol diaacrylate, 4,4'-trimethylene dipiperidine and 1-(3-Aminopropyl) imidazole. This copolymer (Figure 8, top) was used to encapsulate the model protein albumin (Alb). The Albloaded micelles, with sizes in the range of 50 to $70 \mathrm{~nm}$, showed a charge conversion from neutral to positive when $\mathrm{pH}$ values were changed from 7.8 to 6.2 , which is compatible with $\mathrm{pH}$ changes observed in cancerous tissue or ischemic tissues. The ability of this PEG-PAE-API to deliver protein in vivo in acidic tissues was assessed in a rat model of cerebral ischemia. Following intravenous injection with Cy5.5-Alb-loaded micelles a gradual increase in fluorescence signals of the brain ischemic area was observed (Figure 8, bottom), indicating that protein/PEG-PAE-API could be effective for targeting acidic environments and diagnostic imaging [96].



Figure 5. In vivo diffusion-weighted MRI (DW-MRI), near-infrared fluorescence (NIRF) images and signal quantification. In the coronal cross-sectional NIRF images of rat brains of group A (rats injected with PEG-PAE-API-albumin-Cy5.5) (A) and group B (rats injected with albumin-Cy5.5) (B), albumin-Cy5.5 accumulation is clearly visible in the ischemic area of the 
right hemisphere, which can be identified as hyperintense lesion on the DW-MRI, in comparison to the left hemisphere.( adapted with permission from [96]).

Mahmud et al. synthesized in 5 steps a family of PEO- $b$-poly( $\alpha$-carboxyl- $\varepsilon$-caprolactone) DHBCs via ring opening polymerization of $\alpha$-benzyl carboxylate- $\varepsilon$-caprolactone and CL with methoxy-PEO as an initiator, followed by catalytic debenzylation of the protected copolymer (Figure 7 3) [90]. The copolymer with $40 \%$ of carboxylated CL units assembled to spherical micelles with a CMC of $1.2 \times 10^{-2} \mathrm{mM}$ and average diameters of $25 \mathrm{~nm}$. According to the authors, this system could be used as delivery systems for the chemical conjugation, optimized solubilization, and controlled delivery of therapeutic agents.

Deng et al. synthesized methoxy poly(ethyleneglycol)- $b$-poly( $\varepsilon$-caprolactone-co- $\gamma$-dimethyl maleamidic acid- $\varepsilon$-caprolactone) (mPEG- $b$-P(CL-co-DCL) in 3 steps, having a polyester moiety carrying different amounts of acid-labile $\beta$-carboxylic amides (Figure 7 4) [97].

The copolymer formed stable micelles in water with diameters of 100 to $150 \mathrm{~nm}$ and with critical micellar concentrations (CMCs) of 3.2-6.3 $\mu \mathrm{g} / \mathrm{mL}$. The DL and EE of this copolymer for DOX were 3-4 times higher than those of amphiphilic copolymer mPEG-b-PCL micelles. The mPEG- $b$-P(CL-co-DCL) polymer micelles are negatively charged and stable in neutral solution, but, because of the hydrolysis of the $\beta$-carboxylic amides in acidic conditions $(\mathrm{pH}=6.0)$ the polymer becomes positively charged (Figure $\left.74^{\prime}\right)$. This negative to positive charge reversal triggered by the variation of the $\mathrm{pH}$ led to a very fast drug release under acidic conditions, and also improved the cellular uptake by electrostatic absorptive endocytosis. Also, the hydrolysis of the acidic group in the polyester upon $\mathrm{pH}$ decrease from 7.4 to 5.4 led to a faster release in acidic environment (already mentioned). The mPEG- $b$-P(CL-co-DCL) micelles showed a very low cytotoxicity up to a concentration of $1 \mathrm{mg} / \mathrm{mL}$. 
Zhuo et al. used a thiol-ene "click" reaction between pendent carbon-carbon double bonds of mPEG- $b$-poly(5-allyloxytrimethylethylenecarbonate) (mPEG- $b$-PATMC) and various thiolbearing molecules to prepare four different acid modified copolymers mPEG- $b$-PATMC- $g$ SRCOOH $\left(\mathrm{R}=\mathrm{CH}_{2}, \mathrm{CH}_{2} \mathrm{CH}_{2},\left(\mathrm{CH}_{2}\right)_{10}\right.$ and $\left.\mathrm{CH}(\mathrm{COOH}) \mathrm{CH}_{2}\right)$, denoted as P1, P2, P3 and P4, Figure 9 1) [98]. The micelles mean diameters determined by DLS for all the copolymers were below $130 \mathrm{~nm}$, and by TEM the authors showed that the copolymer micelles were dispersed in spherical shape with average diameters from 25 to $35 \mathrm{~nm}$ (Figure 9 2). The negatively charged copolymers were used for the encapsulation of the positively charged drug DOX via synergistic hydrophobic and electrostatic interactions. The DL of the acid-modified copolymer micelles were all higher than $10 \%$ and the EE were higher than $60 \%$. The DOX-loaded copolymer micelles showed a pH-dependent release behavior. After 50 hours, the release was limited to $20 \%$ at $\mathrm{pH} 7.4$ against ca. $70 \%$ at $\mathrm{pH}$ 5.0. Overall, the copolymer P3 with the 11mercaptoundecanoic moieties was the best candidate for DOX formulation as it showed a lower CMC value, smaller particle size, good stability and blood compatibility, as well as higher drug loading capacity. Moreover, cellular investigations revealed an efficient cancer cellular uptake and potent cytotoxic activity of DOX-loaded micelles based on P3 copolymer, probably due to a suitable hydrophobicity and charge density [98]. 
1)<smiles>CCOC(=O)OCC(COCCOC)OCSCC(=O)O</smiles>

2)

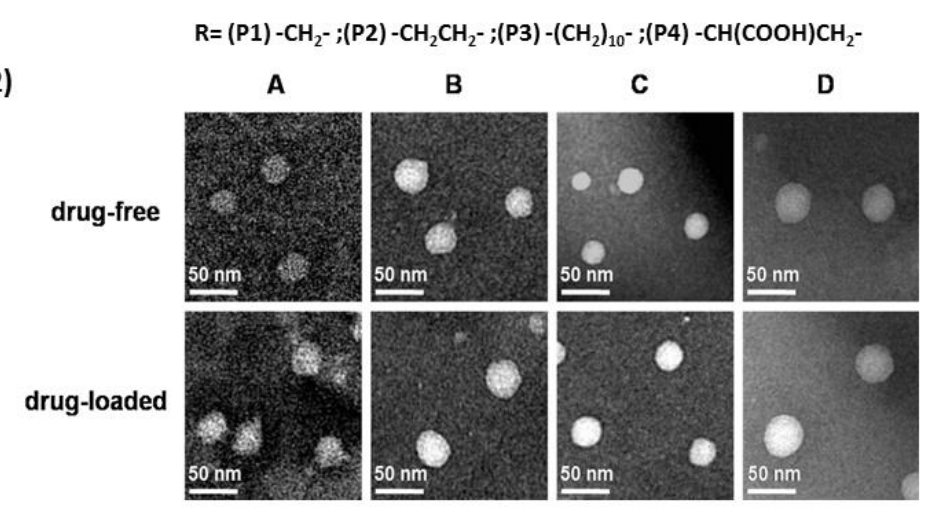

Figure 6. 1) Structure of 4 different acid modified copolymers mPEG-b-PATMC-g-SRCOOH. 2) Transmission electron microscope images of drug-free and drug-loaded polymeric micelles based on (A) P1, (B) P2, (C) P3 and (D) P4. (adapted with permission from [98]).

Zhang et al. prepared PEG- $b$-poly(lactic acid-co-malic acid) (Figure 7 5) copolymers via polycondensation between D,L-lactic acid (LA), L-malic acid (MAL), and monomethyl polyethyleneglycol using stannous chloride $\left(\mathrm{SnCl}_{2}\right)$ as the catalyst [99]. The copolymer was used to encapsulate the DOX via electrostatic interactions between the carboxyl side group of MAL units and the amino groups of DOX. The DL was $18.2 \%$ with good stability in aqueous solution, and TEM images showed spherical nanoparticles in a size range of 110-140 nm. The cumulative DOX release increased under acidic conditions because of the protonation of the acidic group in the MAL. This effect was however limited as after 60 hours, $80 \%$ of the DOX was released at $\mathrm{pH} 7.4$, against $94 \%$ at $\mathrm{pH} 5.8$.

Zhang et al. prepared a pH-responsive amphoteric block copolymer poly(6-acetoxyl- $\varepsilon$ caprolactone)- $b$-poly(4-N-piperilactone) (PCCL- $b$-PPIL) (Figure 7 6) by bulk ring-opening polymerization of 4-N-benzyl formate-piperilactone in the presence of the hydroxyl-terminated 
poly(6-(p-methylbenzyl acetate)- $\varepsilon$-caprolactone) as macroinitiator, followed by removal of the protecting groups. The PCCL- $b$-PPIL copolymer contains carboxyl groups and secondary amine groups in each segment, leading to protonation of the secondary amine groups of the PPIL segments at $\mathrm{pH}<5.7$ and the formation of PCCL-core micelles. At $\mathrm{pH}>6.8$ the carboxyl groups of the PCCL segments were deprotonated and PPIL-core aggregates were formed. Noteworthy, the morphology of the self-assemblies changed from spherical at $\mathrm{pH} 5$ with a diameter of $65 \mathrm{~nm}$ to worm-like micelle upon $\mathrm{pH}$ increase to 8 . Thanks to the carboxyl and the secondary amine groups, fluorescent molecules were attached to the copolymer to form stimuliresponsive fluorescent materials [100].

Our group recently reported on a straightforward, 3-step synthetic strategy for the preparation of DHBCs with PCL blocks containing carboxylic acid, amine or hydroxyl functional moieties [101]. PEG- $b$-PCL copolymers were prepared via ROP of CL employing mPEG as macroinitiator, followed by post-polymerization functionalization of the PCL blocks with pendant alkyne groups using an anionic modification technique [102,103]. Reaction of the alkyne groups with mercaptosuccinic acid, 4,5-diamino-6-hydroxy-2-mercaptopyrimidine or 1thioglycerol via thiol-yne photoaddition resulted in PEG- $b$-PCL copolymers with carboxylic acid, amine or hydroxyl functionalized PCL blocks, respectively (Figure 10a). For PEG $\mathrm{P}_{1.9 \mathrm{k}}-b$ $\mathrm{PCL}_{1.1 \mathrm{k}}(\mathrm{OH})_{52}$ (containing $52 \%$ of hydroxyl groups with respect to CL units) no $\mathrm{pH}$ dependency was expected and therefore its aqueous solution behavior was only tested at $\mathrm{pH}$ 7.4. This copolymer self-assembled into micelles above the CMC of $1 \mathrm{mg} / \mathrm{mL}$ with a diameter of 225 nm. $\mathrm{PEG}_{1.9 \mathrm{k}}-b-\mathrm{PCL}_{1.3 \mathrm{k}}(\mathrm{COOH})_{55}$ and $\mathrm{PEG}_{1.8 \mathrm{k}}-b-\mathrm{PCL}_{1.4 \mathrm{k}}\left(\mathrm{NH}_{2}\right)_{58}$ (containing $55 \%$ of carboxylic acid and $58 \%$ of amine groups with respect to $\mathrm{CL}$ units, respectively) self-assembled into $\mathrm{pH}$ responsive micelles with sizes ranging from $\sim 190 \mathrm{~nm}$ (in case of ionized DHBCs) to $\sim 130 \mathrm{~nm}$ (in case of non-ionized DHBCs). $\mathrm{PEG}_{1.9 \mathrm{k}}-b-\mathrm{PCL}_{1.3 \mathrm{k}}(\mathrm{COOH})_{55}$ formed stable PIC micelles with DOX at $\mathrm{pH}$ 7.4. When the $\mathrm{pH}$ was decreased to 5.0, the PIC micelles disassembled due to the 
loss of electrostatic interactions between DOX and the carboxylic groups on the DHBC, leading to the release of the drug. The DOX loaded PIC micelles were highly cytotoxic towards MCF7 cancer cells (Figure 10b), demonstrating the potential of this type of degradable DHBC for the intracellular delivery of electrostatically charged, hydrophobic drugs.

(a)
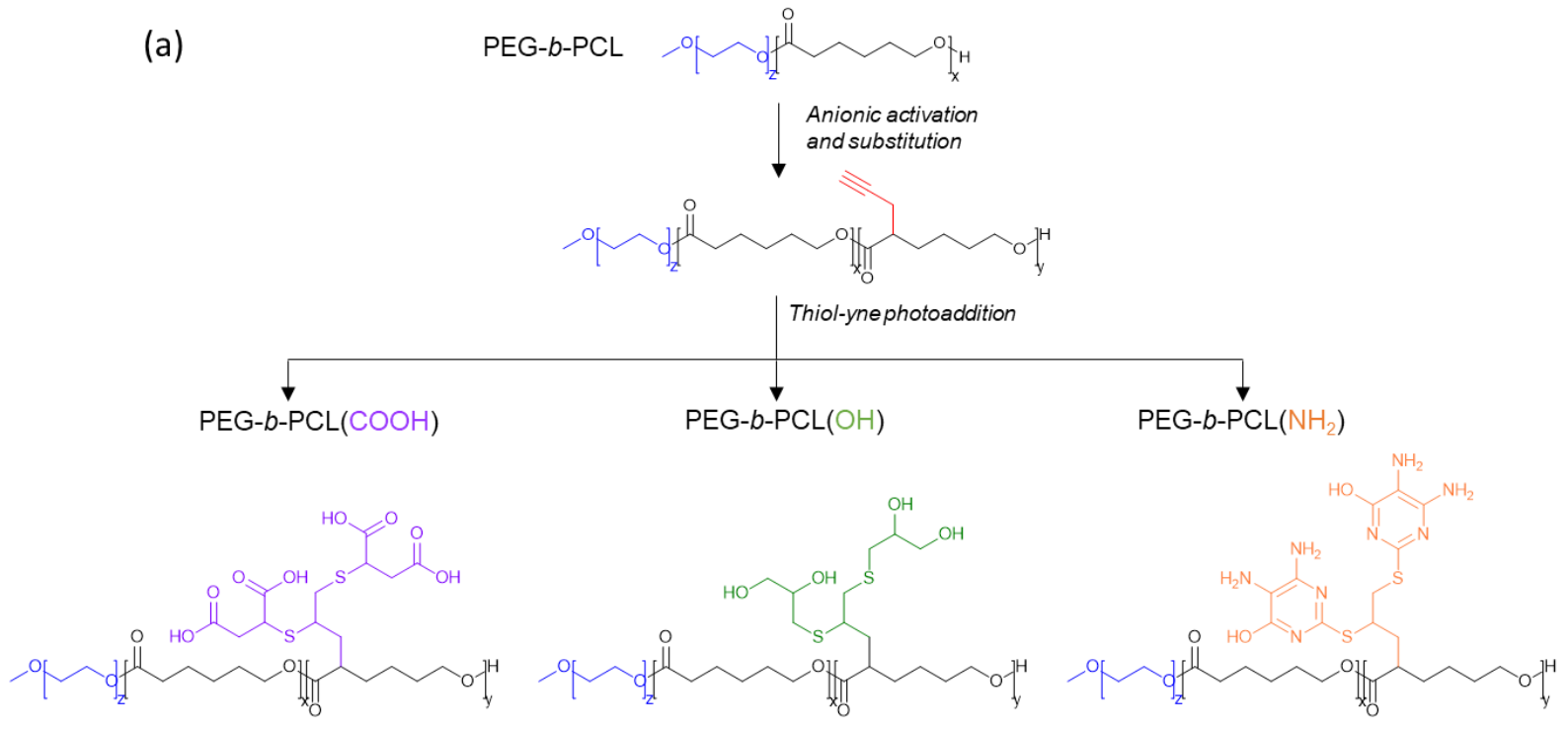

(b)


Figure 7. (a) Synthesis of carboxylic acid, amine or hydroxyl functionalized DHBCs from mPEG- $b$-PCL in 2 steps and (b) illustration of mPEG- $b$-PCL(COOH)/DOX PIC micelles formation and their internalization in MCF-7 cancer cells (adapted with permission from [101]).

Zeynep et al. synthesized DHBCs composed of a PEO block and a polyphosphoester block by a combination of organocatalyzed ring opening polymerization, thiol-yne click chemistry and protection/deprotection methods. They prepared poly(phosphotriester)s bearing pendent carboxylic acids (PEO- $b$-PBYPCOOH) with an affinity for calcium by ROP of butynyl phospholane, as well as poly(phosphodiester)s with a negatively charged oxygen atom on each repeating monomer unit (PEO- $b$-PPDO') by ROP of allyl phospholane (Figure 77 and 7'). The 
authors exploited this family of DHBCs to formulate $\mathrm{CaCO}_{3}$ particles, that can be used for encapsulation, and showed an efficient decrease of particle sizes by a factor of 6 while preventing their aggregation compared to formulations with hyaluronic acid (HA) [104]. In a follow up work, the authors reported on lysozyme-loaded $\mathrm{CaCO}_{3}$ particles prepared via a supercritical $\mathrm{CO}_{2}$ process, where $\mathrm{CO}_{2}$ serves as a source of carbonate ions, using either PEO$b$-PBYPCOOH or HA as templating agent. With PEO- $b$-PBYPCOOH a twice higher loading of active lysozyme was obtained in the particles compared to HA. Furthermore, a smaller size and a deeper encapsulation of lysozyme in the particle core was observed as well as a more efficient incorporation of the protein (Figure 11) [105].
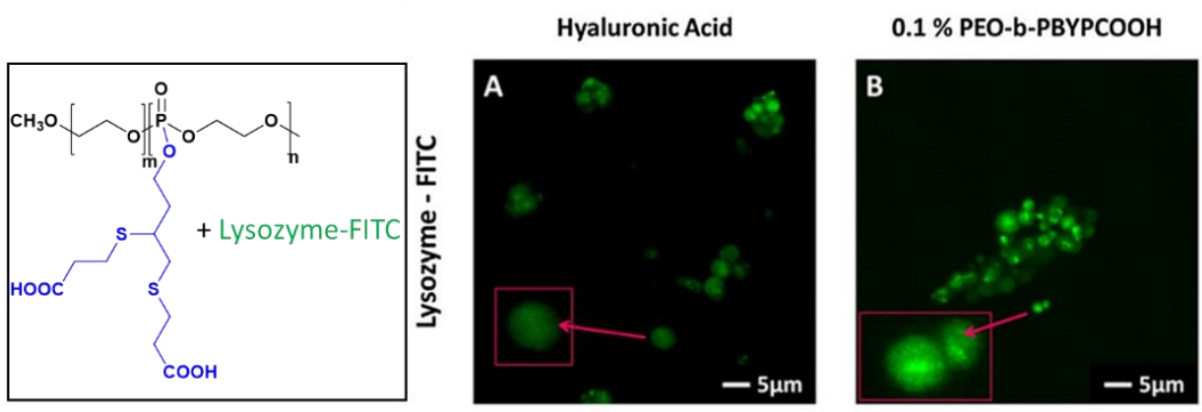

$1 \%$ PEO-b-PBYPCOOH

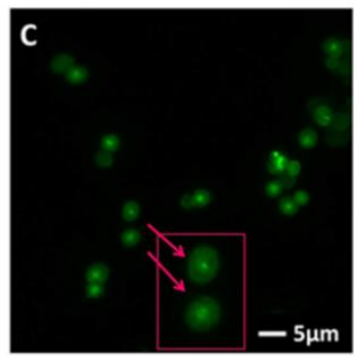

Figure 8. Confocal images of $\mathrm{CaCO}_{3}$ particles with lysozyme-FITC in the presence of (A) 0,1 $\% \mathrm{HA}$; (B) $0.1 \%$ PEO-b-PBYPCOOH and (C) $1 \%$ PEO-b-PBYPCOOH (adapted with permission from [105]).

In another study, poly(2-(2-aminoethoxy)ethoxy)phosphazene (PAEP) was coupled to folatePEG-COOH or mPEG-COOH using a DCC/NHS activation (Figure 7 8). DNA was condensed by the resulting cationic PEG-PAEP DHBCs at various N/P ratios to form PEG-PAEP/DNA polyplexes that were compared with PAEP/DNA polyplexes. It was shown that the pegylation of the PAEP decreased the cytotoxicity toward Hela cells and improved the transfection efficiency [106]. 
Table 5: Characteristics of the self-assemblies obtained with polyester-based degradable double hydrophilic block copolymers.

\begin{tabular}{|c|c|c|c|c|c|}
\hline \multirow{2}{*}{ DHBC } & \multicolumn{3}{|c|}{ Self-assemblies } & \multirow[t]{2}{*}{ Stability / Degradationa } & \multirow[t]{2}{*}{ Ref. } \\
\hline & Type & Preparation & Characteristics $^{\mathbf{a}}$ & & \\
\hline $\mathrm{mPEG}-b-\mathrm{P}\left(\gamma-\mathrm{NH}_{2}-\mathrm{CL}\right)$ & $\begin{array}{l}\text { pH-responsive } \\
\text { micelles }\end{array}$ & $\begin{array}{l}\text { direct dissolution in } \\
\text { water } \\
\text { precipitation method: } \\
\text { addition of EXP water }\end{array}$ & $\begin{array}{l}\mathrm{D}_{h} \sim 50-250 \mathrm{~nm} / \xi \text { potential - } \\
10 \text { to } 30 \mathrm{mV}\end{array}$ & diass. $\leq$ pH $5 \leq$ ass & [93] \\
\hline $\begin{array}{l}\text { PEG- } b-(\mathrm{P}(\mathrm{TMACL}- \\
c o-\mathrm{CL}))_{2}\end{array}$ & $\begin{array}{l}\text { EXP-loaded PIC } \\
\text { micelles }\end{array}$ & $\begin{array}{l}\text { solution in DMF } \\
\text { solution of DHBC (with } \\
20 \% \text { TMA), dialysis } 24 \mathrm{~h} \\
\text { vs. water }\end{array}$ & $\begin{array}{l}\mathrm{D}_{h} \sim 290 \pm 80 \mathrm{~nm} / \xi \text { potential } \\
4 \mathrm{mV} / \mathrm{EE} \sim 87 \% / \mathrm{DL} \sim 8 \%\end{array}$ & $\begin{array}{l}\text { not evaluated for EXP-loaded } \\
\text { micelles. }\end{array}$ & [94] \\
\hline PEG- $b$-PAE-API & $\begin{array}{l}\text { Alb-loaded PIC } \\
\text { micelles }\end{array}$ & $\begin{array}{l}\text { solution of Alb and } \\
\text { DHBC (1:10) in PBS at } \\
\text { pH } 6 \text { followed by } \mathrm{pH} \\
\text { neutralization at } \mathrm{pH} 7.4\end{array}$ & $\begin{array}{l}\mathrm{D}_{h} \sim 50-70 \mathrm{~nm} / \xi \text { potential } \sim 0 \\
\mathrm{mV} / \mathrm{EE} \sim 87 \% / \mathrm{DL} \sim 8 \%\end{array}$ & $\begin{array}{l}\sim 30 \% \text { size decrease when } \mathrm{pH} \geq \\
6.9 . \\
\sim 20 \% \text { size increase from water } \\
\text { to } \mathrm{NaCl} 150 \mathrm{mM} .\end{array}$ & [96] \\
\hline $\begin{array}{l}\mathrm{PEO}-b-\mathrm{P}(\alpha-\mathrm{COOH}- \\
\mathrm{CL}-c o-\mathrm{CL})\end{array}$ & micelles & $\begin{array}{l}\text { precipitation method: } \\
\text { addition of acetone } \\
\text { solution of DHBC in } \\
\text { water followed by } \\
\text { solvent evaporation }\end{array}$ & $\begin{array}{l}\mathrm{D}_{h} \sim 20-38 \mathrm{~nm} \text { with second } \\
\text { population }(\mathrm{ca} .50 \%) \text { with } \mathrm{D}_{h^{\sim}} \\
260-370 \mathrm{~nm} / \mathrm{CMC} \sim 44 \times 10^{-2} \\
\mu \mathrm{M}-1.2 \times 10^{-2} \mathrm{mM}\end{array}$ & not evaluated. & {$[90]$} \\
\hline $\begin{array}{l}\text { mPEG- } b-\mathrm{P}(\mathrm{CL}-c o- \\
\mathrm{DCL}\end{array}$ & $\begin{array}{l}\text { DOX-loaded PIC } \\
\text { micelles }\end{array}$ & $\begin{array}{l}\text { precipitation method: } \\
\text { DMF solution of DHBC } \\
\text { and DOX added in } \\
\text { water followed by } \\
\text { dialysis vs. PBS }\end{array}$ & $\begin{array}{l}\text { Unloaded micelles : CMC 3- } \\
6 \mu \mathrm{g} / \mathrm{mL} / \mathrm{D}_{h} \sim 115-150 \mathrm{~nm} / \xi \\
\text { potential } \sim 14 \mathrm{mV}(\mathrm{pH} 7.4) \\
\text { DOX-loaded micelles : } \mathrm{D}_{h} \sim \\
110-136 \mathrm{~nm} / \xi \text { potential -7 } \\
\mathrm{mV}(\mathrm{pH} 7.4) / \mathrm{EE} \sim 58-84 \% / \\
\mathrm{DL} \sim 9-13 \%\end{array}$ & $\begin{array}{l}\text { hydrolysis of acid-labile } \beta \text { - } \\
\text { carboxylic amides at pH } 6 \text {. } \\
90 \% \text { DOX release at } \mathrm{pH} 5.5 \\
\text { after } 6 \mathrm{~h} v s . \sim 10 \% \text { at } \mathrm{pH} 7.4 \\
\text { after } 24 \mathrm{~h} \text {. }\end{array}$ & [97] \\
\hline $\begin{array}{l}\text { mPEG- } b \text {-PATMC- } g- \\
\text { SRCOOH }\end{array}$ & $\begin{array}{l}\text { DOX-loaded PIC } \\
\text { micelles }\end{array}$ & $\begin{array}{l}\text { dialysis method : DMF } \\
\text { solution of DOX.HCl, } \\
\text { Et }_{3} \mathrm{~N}, \mathrm{DHBC} \text { dialysed } \\
\text { vs. water } 24 \mathrm{~h}\end{array}$ & $\begin{array}{l}\text {. Unloaded micelles : CMC } \\
\text { 3-78 mg/mL / } \mathrm{D}_{h} \sim 73-125 \mathrm{~nm} / \\
\xi \text { potential -10 to }-17 \mathrm{mV} \\
\text {. DOX-loaded micelles : } \mathrm{D}_{h^{\sim}} \\
83-142 \mathrm{~nm} / \xi \text { potential } \sim-4 \text { to - }\end{array}$ & $\begin{array}{l}35-65 \% \text { DOX release at } \mathrm{pH} 5 \\
v s . \sim 20 \% \text { at } \mathrm{pH} 7.4 \text { after } 48 \mathrm{~h} \text {. } \\
33 \% \text { to } 66 \% \text { increase of } \mathrm{DOX} \\
\text { release with } 0.1 \text { and } 0.5 \mathrm{M}\end{array}$ & [98] \\
\hline
\end{tabular}


$8 \mathrm{mV} / \mathrm{EE} \sim 60-91 \%$ / DL 10$16 \%$

mPEG- $b$-P(LA- $c o$ MAL)

PCCL- $b$-PPIL

mPEG- $b$-P(CL- $c o$ $\left.\mathrm{CL}(\mathrm{COOH})_{2}\right)$

\section{PEO- $b$-PBYPCOOH}

Lys-loaded $\mathrm{CaCO}_{3}$ particles

pDNA-loaded polyplexes

zwitterionic $\mathrm{pH}-$ addition of DOX.HCl,

$\mathrm{Et}_{3} \mathrm{~N}$ water solution in

DHBC water solution,

dialysis $v s$. water $24 \mathrm{~h}$ responsive micelles

direct dissolution of DHBC in water

\section{DMF solution of}

DOX.HCl, Et ${ }_{3} \mathrm{~N}, \mathrm{DHBC}$ added in water, dialysis vs. water and PBS 24h

mixing of a $\mathrm{CaCl}_{2}$ DHBC and Lys in glycine buffer, and injection in $\mathrm{scCO}_{2}$ vortexing of $\mathrm{DHBC}$ and pDNA solutions $(\mathrm{R}=$ 15-25)

\section{$\mathrm{D}_{h} \sim 110-140 \mathrm{~nm}$ (TEM) / CAC} $0.8 \mathrm{~g} / \mathrm{L} / \mathrm{DL} \sim 18 \%$

. $\mathrm{pH}<5$ spherical micelles with $\mathrm{D}_{h} \sim 100 \mathrm{~nm} / \xi$ potential 10 to $60 \mathrm{mV}$

. $\mathrm{pH}>8$ worm-like micelles with $\mathrm{D}_{h} \sim 200 \mathrm{~nm} / \xi$ potential 10 to $-40 \mathrm{mV}$

. Unloaded micelles : CMC $0.9-1.7 \mathrm{mg} / \mathrm{mL} / \mathrm{D}_{h} \sim 190-220$ $\mathrm{nm} / \xi$ potential $\sim 30 \mathrm{mV}(\mathrm{pH}$ 7.4)

. DOX-loaded micelles : EE $30-69 \%$ / DL 4.5-10\%

vaterite particles $D_{h} \sim 2 \mu \mathrm{m} / \xi$ potential $\sim 1.5$ to $-10 \mathrm{mV}$

$\mathrm{D}_{h} \sim 88-110 \mathrm{~nm} / \xi$ potential $7.5 \mathrm{mV}$
$\mathrm{NaCl}$ compared to no $\mathrm{NaCl}$, respectively.

$94 \%$ DOX release at $\mathrm{pH} 5.8$ $v s . \sim 80 \%$ at $\mathrm{pH} 7.4$ after $70 \mathrm{~h}$. $90 \%$ DOX release at $0.9 \%$ $\mathrm{NaCl} v s . \sim 55 \%$ at $0.3 \% \mathrm{NaCl}$ after $70 \mathrm{~h}$.

$\mathrm{pH}<5.7$ micelles with PCCL core and cationic PPIL corona $\mathrm{pH}>6.8$ micelles with PPIL core and anionic PCCL corona.

precipitation for $5.7<\mathrm{pH}<$ 6.8.

$75 \%$ DOX release at $\mathrm{pH} 5.0$ after $8 \mathrm{~h} v s . \sim 25 \%$ at $\mathrm{pH} 7.4$ after $24 \mathrm{~h}$.

degradation in water after $24 \mathrm{~h}$ plateau of Lys release at $\sim 60 \%$ after $90 \mathrm{~min}$.

$[104$

not evaluated.

Abbreviations : Alb Albumin ; DOX doxorubicin ; EXP enoxaparin ; FA folate ; Lys Lysozime ; PAE-API poly( $\beta$-aminoester)-1-(3-aminopropyl)imidazole ; PAEP poly(2(2-aminoethoxy)ethoxy)phosphazene ; PATMC, poly(5-allyloxytrimethylethylenecarbonate); PCCL- $b$-PPIL poly(6-acetoxyl- $\varepsilon$-caprolactone)- $b$-poly(4-N-piperilactone); $\mathrm{P}\left(\mathrm{CL}-\mathrm{co}-\mathrm{CL}(\mathrm{COOH})_{2}\right)$ poly $(\varepsilon$-caprolactone-co- $\alpha--\varepsilon$-caprolactone $) ; \mathrm{P}(\mathrm{CL}-c o-\mathrm{DCL})$ poly $(\varepsilon$-caprolactone-co- $\gamma$-dimethyl maleamidic acid- $\varepsilon$-caprolactone $) ; \mathrm{P}(\alpha-\mathrm{COOHCL}-c o-$ CL) Poly $\left(\alpha\right.$-carboxyl- $\varepsilon$-caprolactone-co- $\varepsilon$-caprolactone ; Poly $(\alpha$-carboxyl- $\varepsilon$-caprolactone $) ; \mathrm{P}\left(\gamma-\mathrm{NH}_{2}\right.$-CL) Poly( $\gamma$-amino- $\varepsilon$-caprolactone $)$; P(TMACL-co-CL) Poly(trimethyl

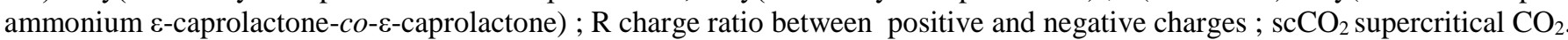

a ranges of provided values correspond to characteristics obtained as a function of the blocks' length of the used DHBCs and/or ratios of compounds. If not specified sizes correspond to the hydrodynamic diameters or radii measured by DLS. 


\section{DHBCs for biomedical applications: unique advantages, current challenges and future perspectives}

As illustrated in the course of this review, DHBCs are well-suited for biomedical use. This resides in their wide applicability in aqueous systems explained by some key advantages compared to classical amphiphilic systems. A first advantage is the chemical flexibility offered by the functional block that can be synthesized in such a way that it becomes amphiphilic in response to a stimulus. Temperature and $\mathrm{pH}$ have been largely exemplified in this work and are the two main parameters considered for triggering the change of macromolecular conformation in water, especially for drug delivery. However, ionic strength and the nature of the counter ions can also be considered, for example in the case of zwitterionic DHBCs [107] or of DHBCs exhibiting self-assembly upon addition of metal ions to form supramolecular hydrogels [108]. Another physical trigger rising more and more focus in drug delivery is light. Classically, light is used to activate dimerization, cleavage or conformational transition of light-sensitive constituents of the macromolecular structure which allows disassembly or swelling of the drug delivery system leading to release of their payload [109]. This approach has rarely been reported for DHBCs with only few examples of soluble coumarin-functional DBHCs being turned into insoluble nanogels with a controllable degree of swelling thanks to a coumarin-based reversible UV-crosslinking [110,111]. Light-trigger could also be used to generate DHBCs as exemplified by $\mathrm{Wu}$ et al. who took advantage of the photocleavable nitrobenzyl moiety [112]. Upon UV irradiation, a block containing 5-(2-(dimethylamino)ethoxy)-2-nitrobenzyl acrylate units was turned into a hydrophilic water-soluble block bearing hydrophilic acrylic acid groups, which led to the formation of a DHBC. This last example illustrates the potential of light to generate DHBCs in situ. Of notice, no examples of light-responsive degradable DHBCs are described to date which constitutes to our opinion an unexplored opportunity. However, further development of light-responsive DHBCs for biomedical applications raises the critical question of the 
cytocompatibility of the photosensitive groups and the byproducts generated upon their photoactivation.

Coming to the biomedical applications, like their amphiphilic counterparts DHBCs can be found in a large array of applications including medical imaging $[13,113]$, sensing of external microenvironment $[112,114]$, theranostics [115] and most of all in drug and gene delivery as largely exemplified in this review with numerous examples of PIC micelles. A second key advantage of DHBCs explain their success in this domain. Many relevant substrates, including drugs and biomolecules, are hydrophilic (although not necessarily water soluble), contain groups allowing electrostatic interactions and are present in aqueous environments. To address such substrates, the soundest molecular design of a surfactant is that of a DHBC as they can accommodate higher loadings and guaranty their load retention compared to more conventional nano-carriers (such as core-shell micelles from amphiphilic copolymers) by forming PIC micelles thanks to electrostatic interactions between the polymer and the cargo molecule. In addition, the stimulus-responsiveness of the functional block allows for on-demand drug or gene release within short times and with high efficiency. Of notice, this stimuli-responsiveness being also responsible for the transition of the functional block from a hydrophilic to a hydrophobic block, it allows DHBCs to accommodate hydrophobic cargos as well. This feature makes them highly versatile as most active pharmaceutical ingredients can therefore be encapsulated in DHBCs with proper optimization of the formulations.

Despite the enormous progress that has been achieved in the field, several challenges remain. These will be discussed below together with perspectives how they could be addressed in future research. A first challenge concerns the lack of homogeneity in the conditions used to prepare the DHBC self-assemblies. Although their natures are diverse and do not allow a single 
procedure, it is to note that DHBCs of the same class are not always formulated the same way (dissolution, co-solvatation etc...) which makes the comparison difficult among them. This in in particular true when it comes to drug loading of self-assemblies. For a same drug, various ways of incorporation can generally be found (see Tables 2 to 5), and therefore, the resulting drug loadings cannot be only ascribed to the chemical structure of the DHBCs. This largely hinders the comparison of performances between the DHBCs which on the long term slows down the iterative process of design improvements that can lead to a real breakthrough in drug formulation and delivery.

Secondly, and in relation with the first point, the complex behavior of DHBCs in solution should be pointed out and correlated with their functional behavior. Although this complex behavior is the cornerstone of their applicability as stimuli-responsive systems, most DHBCs are only studied and used by polymer groups with a main interest in the structure design and applications. On the other hand, in the case of DHBC studies by physico-chemists, the dimension of application is generally not considered, with for example in depth studies of solution behaviors of the DHBCs under various conditions, but no study of the corresponding drug-loaded systems (e.g. spatial repartition of drug, drug-polymer interactions etc...) under physiologically relevant conditions (e.g. presence of proteins). It is therefore our opinion that one of the levers for the future developments of DHBCs resides in the combined approaches of both communities.

Thirdly, most of the DHBC systems have only been tested in vitro. This is clearly demonstrated with the works cited in this review, where less than $10 \%$ of the structures reported have been tested in vivo $[13,15,58,72,76,77,81,96]$. To facilitate clinical translation, the therapeutic effects should be studied in vivo together with their toxicity, long-term biodegradability and accumulation. This is especially important for DHBCs carrying cationic moieties since concerns have been raised regarding the in vitro and in vivo toxicity of such polymers [116]. 
Fourthly, the preparation of functional synthetic polymer blocks may be challenging, which cripples reproducibility. It also suffers from low yields due to multi-step reactions, which makes translation into the clinic less feasible. In this regard the use of polysaccharides, which inherently contain pending functional groups that can be easily modified, is particularly attractive for the conception of DHBCs. However, the control of their molecular weight and the difficulty to generate only diblock copolymers and not graft copolymers limits their practical use as illustrated by the low number of polysaccharides-based DHBCs. It is therefore our belief that the development of scale up friendly chemical strategies allowing for a rapid preparation of functional synthetic polymer blocks is one challenge to be tackled by the polymer community. Of notice, post-chemical modifications of selected polymer structures to generate macromolecular diversity appears to be highly attractive, especially with the use of "click chemistry" methodologies, that allow a rapid fine tuning of the polymers' structures $[76,94,98,101,104]$.

Fifthly, concerns exist regarding the immunogenicity of PEG $[117,118]$, which is present in many DHBCs as the water-soluble non-ionic block. These concerns justify the consideration of alternatives for use in DHBCs. Other non-ionic water-soluble blocks such as POx and PVP have been explored, but further research is warranted in terms of e.g. toxicity to investigate whether they can realistically serve as an alternative for PEG. In this regard, in view of the nondegradability of PEG, POx and PVP, a degradable, non-ionic and water-soluble block would represent a significant step forward in the field of biomedical DHBCs.

Lastly, although most polymers reported in this review are considered as degradable due to expected degradability of the backbones of the functional blocks (polypeptides, polyesters etc...), the degradation of these DHBCs is not investigated, even though biodegradability is a key property for polymers in biomedical applications. Despite degradation being highly likely, this degradation may be strongly impacted by the chemical modifications carried out on these 
backbones and the influence of the selected functional groups on the degradation behavior of the DHBCs should be systematically investigated. Future research should therefore provide insight in the mass loss over time of DHBCs as well as the chemical structure and the toxicity of the degradation products both in vitro and in vivo.

\section{Concluding remarks}

Double hydrophilic block copolymers are a class of copolymers with numerous advantages in the frame of drug delivery systems design and drug formulation, including stimuli-responsive self-assembly behavior or improved loadings through electrostatic interactions. In particular, DHBCs exhibiting a functional degradable block chosen among polysaccharides, polypeptides or polyesters can further improve these systems by providing fully bio-eliminable structures. Such degradable DHBCs have demonstrated their potential for various biomedical applications ranging from $\mathrm{pH}$ triggered release of high amounts of drugs and proteins, to efficient delivery of nucleic acids or self-assembly driven templating of inorganic cargos. However, a number of limitations are clearly still present, including the absence of homogeneity in self-assembly testing, missing in vivo data, laborious synthesis of functional polymer blocks and lack of data concerning degradation of DHBCs. Nevertheless, the authors believe that DHBCs will play an increasingly important role in biomedical applications in the years to come thanks to their wide applicability in biological systems, the possibility of stimulus-responsiveness and their high cargo loading. Overall, this review highlights both the potential of degradable DHBCs for advanced drug delivery systems and the opportunities that are still open to further improve these copolymers towards applications at an industrial and clinical level.

\section{Declaration of Competing Interest}

We declare that there is no conflict of interest related to this article. 


\section{Acknowledgements}

This work was partly supported by Research program at the Lebanese University and Lebanese Association for Scientific Research (LASeR) (A.E.J.). 
Table 1 (non-degradable DHBCs): chemical structure of double hydrophilic block copolymers and their biomedical applications (chemical structures are only provided once for each block).

\begin{tabular}{|c|c|c|c|}
\hline $\begin{array}{l}\text { Solubilizing } \\
\text { blocks }\end{array}$ & $\begin{array}{l}\text { Stimuli-responsive } \\
\text { blocks }\end{array}$ & Applications & Ref. \\
\hline PEO & PAA & Self-assembly into giant vesicles & [12] \\
\hline PEO & PAA & Association with gadolinium $\left(\mathrm{Gd}^{3+}\right)$ for imaging & [13] \\
\hline PEO & PMA & Transfection of mesenchymal stem cells using SiRNA & [14] \\
\hline PEO & PAA & Encapsulation of DOX or MTX & [15] \\
\hline PVP & PSMA & Encapsulation of Co A & [17] \\
\hline PVP & PDMAEMA & Formation of PIC-micelles with anionic PVP-DHBCs & [17] \\
\hline PVP & PAMPS & Encapsulation of FA / inorganic phase templating & $\begin{array}{l}{[19,2} \\
1]\end{array}$ \\
\hline PVP & PMA & templating of $\mathrm{CaCO}_{3}$ & [20] \\
\hline PVP & PAPTAC & inorganic phase templating & [21] \\
\hline
\end{tabular}




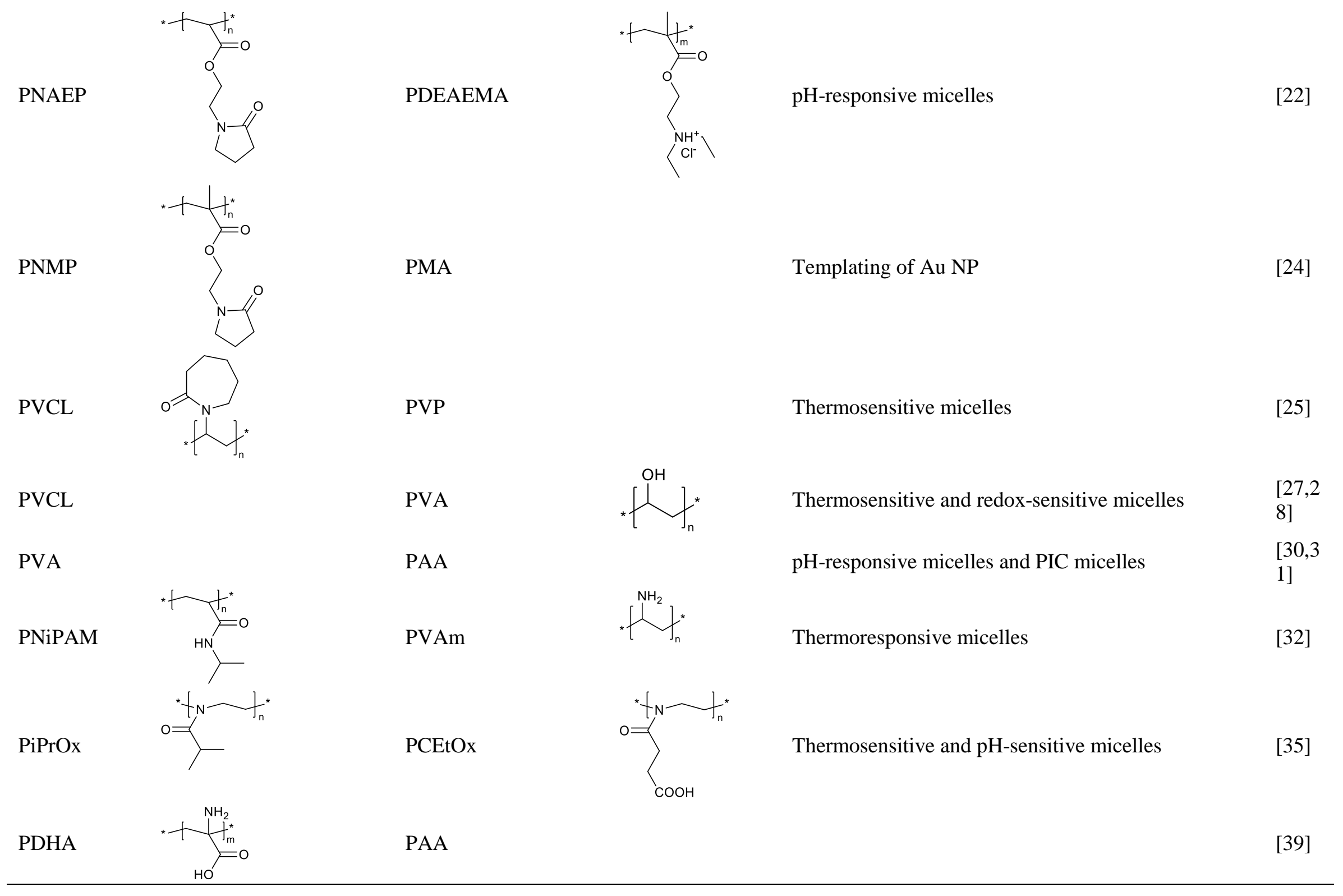


Abbreviations : Co A coenzyme A ; DOX doxorubicin ; MTX mitoxantrone ; PAA poly(acrylic acid) ; PAMPS poly(2-acrylamido-2-methyl-1-propanesulfonic acid) ; PAPTAC poly(3- acrylamidopropyltrimethylammonium chloride) ; PCEtOx poly(2-carboxyethyl-2-oxazoline); PDEAEMA (poly(2-(diethylamino)ethyl methacrylate) ; PDHA poly(dehydroalanine) ; PDMAEMA poly(2-(dimethylamino)ethyl methacrylate); PEG poly(ethylene glycol) ; mPEG monomethoxy-poly(ethylene glycol) ; PEO poly(ethylene oxide); PEtOx Poly(2-ethyl-2-oxazoline); PHPMA poly(N-(2-hydroxypropyl) methacrylamide) ; PiPrOx poly(2-isopropyl-2-oxazoline) ; PMA poly(methacrylic acid); PNAEP poly(2-(N-acryloyloxy)ethylpyrrolidone) ; PNIPAM poly(N-isopropyl acrylamide) ; PNMP poly(N-(2-methacryloylxyethyl) pyrrolidone) ; PSMA poly(styrene-altmaleic anhydride) ; PVA poly(vinyl alcohol) ; PVAm poly(vinyl amine) ; PVCL, Poly(N-vinylcaprolactam) ; PVP poly(vinyl pyrrolidone). 
Table 1 (continued polysaccharide-based degradable DHBCs): Classification and chemical structure of double hydrophilic block copolymers and their biomedical applications (chemical structures are only provided once for each block).

\begin{tabular}{|c|c|c|c|}
\hline $\begin{array}{l}\text { Solubilizing } \\
\text { blocks }\end{array}$ & $\begin{array}{l}\text { Stimuli-responsive } \\
\text { blocks }\end{array}$ & Applications & Ref. \\
\hline PEG & Chitosan & Thermosensitive gel & {$[59]$} \\
\hline mPEG & Oligochitosan & Foreseen for drug delivery applications & {$[60]$} \\
\hline PEG & $\begin{array}{l}\text { Carboxymethyl- } \\
\text { dextran }\end{array}$ & $\begin{array}{l}\text { Encapsulation of diminazene diaceturate, minocycline } \\
\text { hydrochloride, paromomycin and neomycin }\end{array}$ & $\begin{array}{l}{[61-} \\
64]\end{array}$ \\
\hline Dextran & PSAr & $\begin{array}{l}\text { Formation of giant vesicles to be used as model } \\
\text { cells and organelles }\end{array}$ & {$[65]$} \\
\hline Dextran & PEO & $\begin{array}{l}\text { Formation of giant vesicles to be used as model } \\
\text { cells and organelles }\end{array}$ & {$[65]$} \\
\hline Pullulan & PEO & $\begin{array}{l}\text { Formation of giant vesicles to be used as model } \\
\text { cells and organelles }\end{array}$ & {$[65]$} \\
\hline Pullulan & PEtOx & - & {$[66]$} \\
\hline
\end{tabular}

Abbreviations : PEG poly(ethylene glycol); mPEG monomethoxy-poly(ethylene glycol). 
Table1 (continued polypeptide-based degradable DHBCs): degradable double hydrophilic block copolymers and their biomedical applications (chemical structures are only provided once for each block).

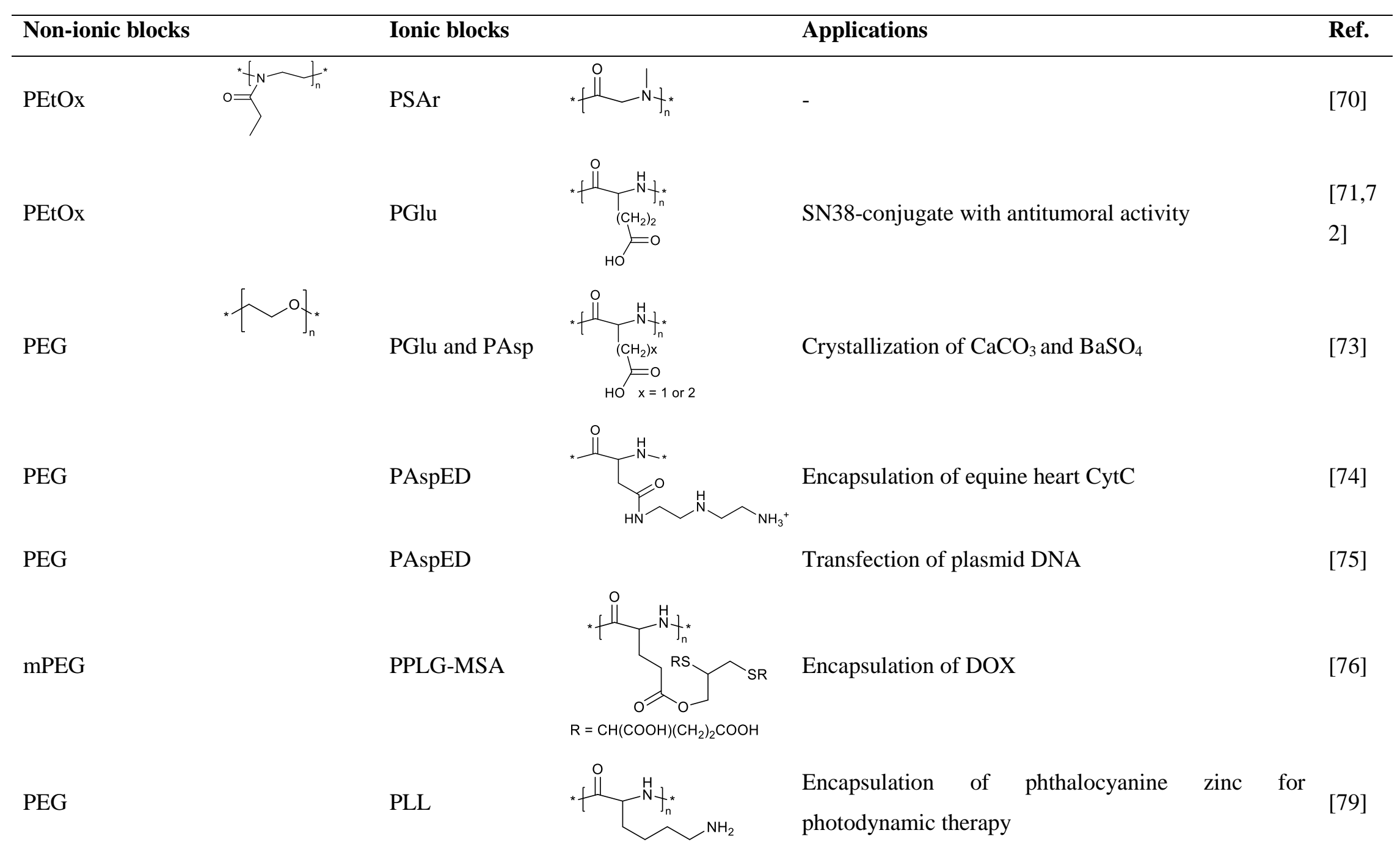


Abbreviations : CytC cytochrome C ; DNA deoxyribonucleic acid ; DOTA 1,4,7,10-tetraazacyclododecane-1,4,7,10-tetraacetic acid ; DOX doxorubicin ; Gd ${ }^{3+}$ gadolinium ion ; PAsp poly(aspartic acid) ; PAspED poly(aspartic acid(ethylene diamine)); PEtOx, poly(2-ethyl-2-oxazoline) ; PGlu poly(L-glutamic acid) ; PLL poly(lysine) ; PPLGMSA poly( $\gamma$-propargyl-L-glutamate- $g$-mercaptosuccinic acid) ; PSar poly(sarcosine) ; SN38 7-Ethyl-10-hydroxy camptothecin. 
Table1 (continued polyester-based degradable DHBCs): degradable double hydrophilic block copolymers and their biomedical applications (chemical structures are only provided once for each block).

\begin{tabular}{|c|c|c|c|}
\hline $\begin{array}{l}\text { Solubilizing } \\
\text { blocks }\end{array}$ & $\begin{array}{l}\text { Stimuli-responsive } \\
\text { blocks }\end{array}$ & Applications & Ref. \\
\hline $\mathrm{mPEG}$ & $\mathrm{P}\left(\gamma-\mathrm{NH}_{2}-\mathrm{CL}\right)$ & - & [93] \\
\hline PEG & $\begin{array}{l}\mathrm{P}(\alpha-\mathrm{TMA}-\mathrm{CL}-\mathrm{co}- \\
\mathrm{CL})\end{array}$ & Encapsulation of enoxaparin & [94] \\
\hline $\begin{array}{l}\text { Monoacrylated- } \\
\text { PEG }\end{array}$ & PAE-API & Encapsulation of albumin & [96] \\
\hline PEO & $\begin{array}{l}\mathrm{P}(\alpha-\mathrm{COOHCL}-\mathrm{co}- \\
\mathrm{CL})\end{array}$ & & {$[90]$} \\
\hline $\mathrm{mPEG}$ & $\mathrm{P}(\mathrm{CL}-c o-\mathrm{DCL})$ & Encapsulation of DOX & [97] \\
\hline
\end{tabular}




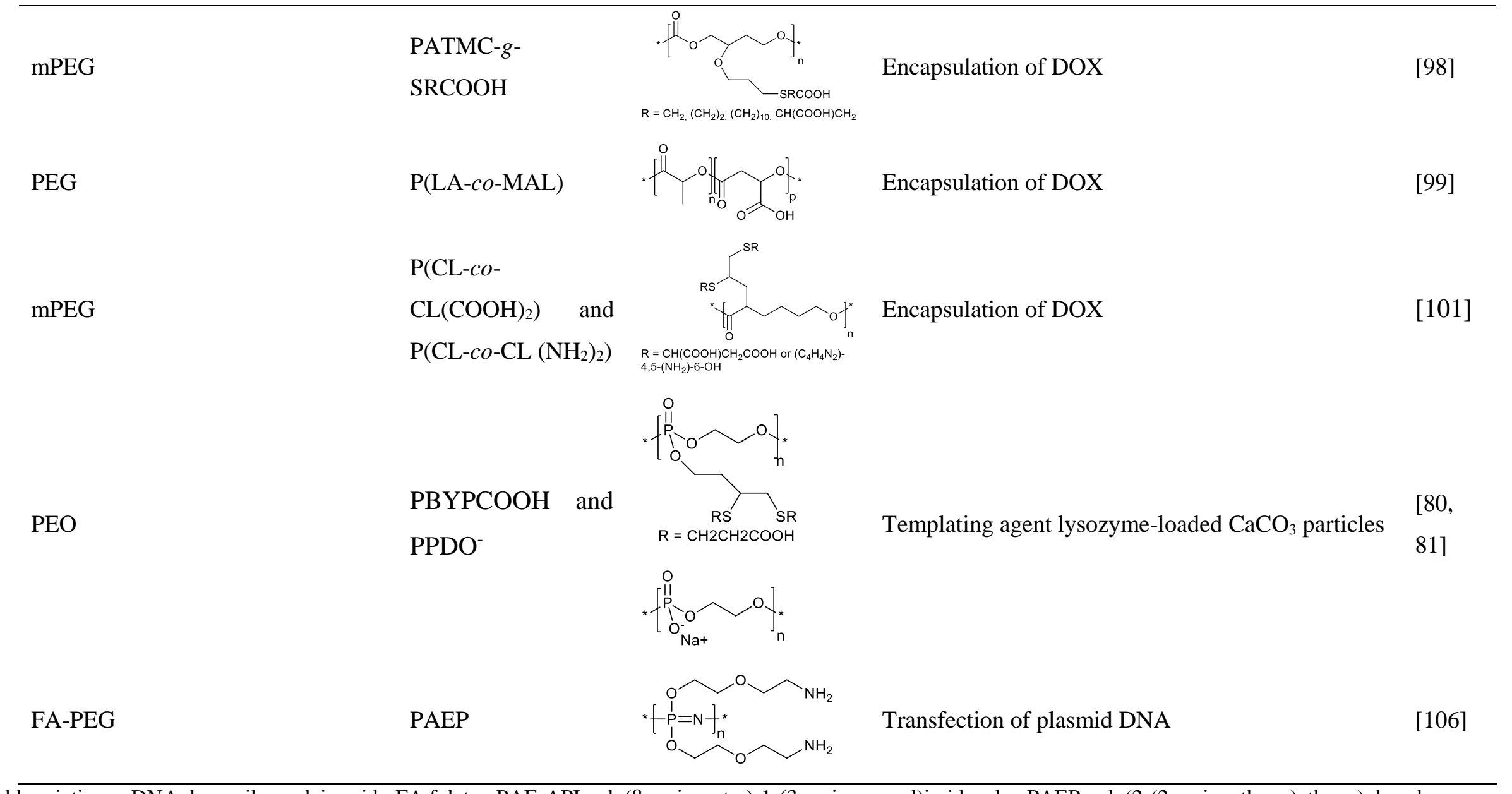

Abbreviations : DNA deoxyribonucleic acid ; FA folate ; PAE-API poly( $\beta$-aminoester)-1-(3-aminopropyl)imidazole ; PAEP poly(2-(2-aminoethoxy)ethoxy)phosphazene ; PATMC, poly(5-allyloxytrimethylethylenecarbonate) ; PBYPCOOH poly(phosphotriester) ; PCCL- $b$-PPIL poly(6-acetoxyl-e-caprolactone)- $b$-poly(4-N-piperilactone) ;

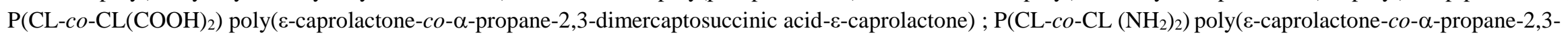

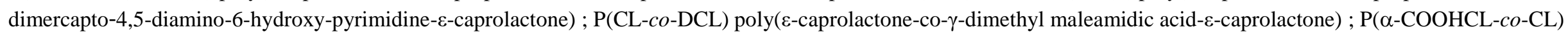

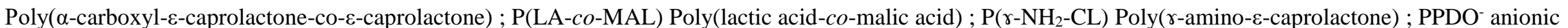
poly(phosphodiester) ; $\mathrm{P}(\alpha$-TMA-CL-co-CL) Poly(trimethyl ammonium $\varepsilon$-caprolactone-co-e-caprolactone) ; 


\section{References:}

[1] Kwon GS, Kataoka K. Block copolymer micelles as long-circulating drug vehicles. Adv Drug Deliv Rev 2012;64:237-45. https://doi.org/10.1016/j.addr.2012.09.016.

[2] Biswas S, Kumari P, Lakhani PM, Ghosh B. Recent advances in polymeric micelles for anti-cancer drug delivery. Eur J Pharm Sci 2016;83:184-202. https://doi.org/10.1016/j.ejps.2015.12.031.

[3] Talelli M, Barz M, Rijcken CJF, Kiessling F, Hennink WE, Lammers T. Core-crosslinked polymeric micelles: Principles, preparation, biomedical applications and clinical translation. Nano Today 2015;10:93-117. https://doi.org/10.1016/j.nantod.2015.01.005.

[4] Kamachi M, Kurihara M, Stille JK. Synthesis of block polymers for desalination membranes. Preparation of block copolymers of 2-vinylpyridine and methacrylic acid or acrylic acid. Macromolecules 1972;5:161.

[5] Cölfen H. Double-hydrophilic block copolymers: synthesis and application as novel surfactants and crystal growth modifiers. Macromol Rapid Commun 2001;22:219.

[6] Harada A, Kataoka K. Polyion complex micelle formation from double-hydrophilic block copolymers composed of charged and non-charged segments in aqueous media. Polym J 2018;50:95.

[7] Abolmaali SS, Tamaddon AM, Salmanpour M, Mohammadi S, Dinarvand R. Block ionomer micellar nanoparticles from double hydrophilic copolymers, classifications and promises for delivery of cancer chemotherapeutics. Eur J Pharm Sci 2017;104:393. https://doi.org/10.1016/j.ejps.2017.04.009.

[8] Schmidt BVKJ. Double Hydrophilic Block Copolymer Self-Assembly in Aqueous Solution. Macromol Chem Phys 2018;219:1700494. https://doi.org/10.1002/macp.201700494.

[9] Yamaoka T, Tabata Y, Ikada Y. Distribution and tissue uptake of poly(ethylene glycol) with different molecular weights after intravenous administration to mice. J Pharm Sci 1994;83:601. https://doi.org/10.1002/jps.2600830432.

[10] Ulbricht J, Jordan R, Luxenhofer R. On the biodegradability of polyethylene glycol, polypeptoids and poly(2-oxazoline)s. Biomaterials 2014;35:4848. https://doi.org/10.1016/j.biomaterials.2014.02.029.

[11] Kawai F. Biodegradation of Polyethers (Polyethylene Glycol, Polypropylene Glycol, Polytetramethylene glycol, and Others). Biopolym Online 2019. https://doi.org/10.1002/3527600035.bpol9012.

[12] Shin SHR, McAninch PT, Henderson IM, Gomez A, Greene AC, Carnes EC, et al. Selfassembly/disassembly of giant double-hydrophilic polymersomes at biologically-relevant $\mathrm{pH}$. Chem Commun 2018.

[13] Frangville C, Li Y, Billotey C, Talham DR, Taleb J, Roux P, et al. Assembly of double-hydrophilic block copolymers triggered by gadolinium ions: new colloidal MRI contrast agents. Nano Lett 2016;16:4069.

[14] Raisin S, Morille M, Bony C, Noël D, Devoisselle J-M, Belamie E. Tripartite polyionic complex (PIC) micelles as non-viral vectors for mesenchymal stem cell siRNA transfection. Biomater Sci 2017;5:1910-21. https://doi.org/10.1039/C7BM00384F.

[15] Ramasamy T, Poudel BK, Ruttala H, Choi JY, Hieu TD, Umadevi K, et al. Cationic drug-based selfassembled polyelectrolyte complex micelles: Physicochemical, pharmacokinetic, and anticancer activity analysis. Colloids Surf B Biointerfaces 2016;146:152-60. https://doi.org/10.1016/j.colsurfb.2016.06.004.

[16] Teodorescu M, Bercea M, Morariu S. Biomaterials of PVA and PVP in medical and pharmaceutical applications: Perspectives and challenges. Biotechnol Adv 2019;37:109-31. https://doi.org/10.1016/j.biotechadv.2018.11.008. 
[17] Luo Y, Yao X, Yuan J, Ding T, Gao Q. Preparation and drug controlled-release of polyion complex micelles as drug delivery systems. Colloids Surf B Biointerfaces 2009;68:218-24. https://doi.org/10.1016/j.colsurfb.2008.10.014.

[18] Luo Y-L, Yuan J-F, Shi J-H, Gao Q-Y. Synthesis and characterization of polyion complex micelles and their controlled release of folic acid. J Colloid Interface Sci 2010;350:140-7. https://doi.org/10.1016/j.jcis.2010.06.014.

[19] Luo Y-L, Yuan J-F, Liu X-J, Hui Xie, Gao Q-Y. Self-assembled Polyion Complex Micelles based on PVP-b-PAMPS and PVP-b-PDMAEMA for Drug Delivery. J Bioact Compat Polym 2010;25:292304. https://doi.org/10.1177/0883911510362459.

[20] Zhang P, Zhong X, Chai Y, Liu Y. The effect of PVP-b-PMAA block copolymer on morphologies control of calcium carbonate. Colloid Polym Sci 2008;286:1135-41. https://doi.org/10.1007/s00396-008-1875-1.

[21] Guinaudeau A, Coutelier O, Sandeau A, Mazières S, Nguyen Thi HD, Le Drogo V, et al. Facile Access to Poly( $N$-vinylpyrrolidone)-Based Double Hydrophilic Block Copolymers by Aqueous Ambient RAFT/MADIX Polymerization. Macromolecules 2014;47:41-50. https://doi.org/10.1021/ma4017899.

[22] Deane OJ, Lovett JR, Musa OM, Fernyhough A, Armes SP. Synthesis of Well-Defined Pyrrolidone-Based Homopolymers and Stimulus-Responsive Diblock Copolymers via RAFT Aqueous Solution Polymerization of 2-( $N$-Acryloyloxy)ethylpyrrolidone. Macromolecules 2018;51:7756-66. https://doi.org/10.1021/acs.macromol.8b01627.

[23] Institute of Biochemistry and Physiology of Plants and Microorganisms, Russian Academy of Sciences, Dykman LA, Khlebtsov NG, Institute of Biochemistry and Physiology of Plants and Microorganisms, Russian Academy of Sciences. Gold Nanoparticles in Biology and Medicine: Recent Advances and Prospects. Acta Naturae 2011;3:34-55. https://doi.org/10.32607/20758251-2011-3-2-34-56.

[24] Zhang J-P, Cheng S-Z, Li X-F, Dong J-F. pH- and Temperature-Induced Micellization of the Dual Hydrophilic Block Copolymer Poly(methacrylate acid)-b-poly(N-(2-methacryloylxyethyl) pyrrolidone) in Aqueous Solution. ACTA Phys-Chim Sin 2016;32:2018-26. https://doi.org/10.3866/PKU.WHXB201605271.

[25] Liang X, Kozlovskaya V, Cox CP, Wang Y, Saeed M, Kharlampieva E. Synthesis and self-assembly of thermosensitive double-hydrophilic poly( $N$-vinylcaprolactam)- $b$-poly( $N$-vinyl-2pyrrolidone) diblock copolymers. J Polym Sci Part Polym Chem 2014;52:2725-37. https://doi.org/10.1002/pola.27291.

[26] Cortez-Lemus NA, Licea-Claverie A. Poly(N-vinylcaprolactam), a comprehensive review on a thermoresponsive polymer becoming popular. Prog Polym Sci 2016;53:1-51. https://doi.org/10.1016/j.progpolymsci.2015.08.001.

[27] Hurtgen M, Liu J, Debuigne A, Jerome C, Detrembleur C. Synthesis of thermo-responsive poly(N-vinylcaprolactam)-containing block copolymers by cobalt-mediated radical polymerization. J Polym Sci Part Polym Chem 2012;50:400-8. https://doi.org/10.1002/pola.25045.

[28] Liu J, Detrembleur C, Hurtgen M, Debuigne A, De Pauw-Gillet M-C, Mornet S, et al. Reversibly crosslinked thermo- and redox-responsive nanogels for controlled drug release. Polym Chem 2014;5:77-88. https://doi.org/10.1039/C3PY00839H.

[29] Debuigne A, Willet N, Jérôme R, Detrembleur C. Amphiphilic Poly(vinyl acetate)- $b-\operatorname{poly}(N$ vinylpyrrolidone) and Novel Double Hydrophilic Poly(vinyl alcohol)- $b$-poly( $N$-vinylpyrrolidone) Block Copolymers Prepared by Cobalt-Mediated Radical Polymerization. Macromolecules 2007;40:7111-8. https://doi.org/10.1021/ma0712908.

[30] Debuigne A, Warnant J, Jérôme R, Voets I, de Keizer A, Cohen Stuart MA, et al. Synthesis of Novel Well-Defined Poly(vinyl acetate)- $b$-poly(acrylonitrile) and Derivatized Water-Soluble Poly(vinyl alcohol)- $b$-poly(acrylic acid) Block Copolymers by Cobalt-Mediated Radical Polymerization. Macromolecules 2008;41:2353-60. https://doi.org/10.1021/ma702341v. 
[31] Voets IK, Keizer A de, Leermakers FAM, Debuigne A, Jérôme R, Detrembleur C, et al. Electrostatic hierarchical co-assembly in aqueous solutions of two oppositely charged double hydrophilic diblock copolymers. Eur Polym J 2009;45:2913-25.

https://doi.org/10.1016/j.eurpolymj.2009.06.020.

[32] Maki Y, Mori H, Endo T. Synthesis of Amphiphilic and Double-Hydrophilic Block Copolymers Containing Poly(vinyl amine) Segments by RAFT Polymerization of $N$-Vinylphthalimide. Macromol Chem Phys 2010;211:45-56. https://doi.org/10.1002/macp.200900332.

[33] Weber C, Hoogenboom R, Schubert US. Temperature responsive bio-compatible polymers based on poly(ethylene oxide) and poly(2-oxazoline)s. Prog Polym Sci 2012;37:686-714. https://doi.org/10.1016/j.progpolymsci.2011.10.002.

[34] Lorson T, Lübtow MM, Wegener E, Haider MS, Borova S, Nahm D, et al. Poly(2-oxazoline)s based biomaterials: A comprehensive and critical update. Biomaterials 2018;178:204-80. https://doi.org/10.1016/j.biomaterials.2018.05.022.

[35] Zschoche S, Rueda JC, Binner M, Komber H, Janke A, Appelhans D, et al. Temperature- and pHdependent aggregation behavior of hydrophilic dual-sensitive poly(2-oxazoline)s block copolymers as latent amphiphilic macromolecules. Eur Polym J 2017;88:623-35. https://doi.org/10.1016/j.eurpolymj.2016.11.014.

[36] Rudolph T, Crotty S, von der Lühe M, Pretzel D, Schubert U, Schacher F. Synthesis and Solution Properties of Double Hydrophilic Poly(ethylene oxide)-block-poly(2-ethyl-2-oxazoline) (PEO-bPEtOx) Star Block Copolymers. Polymers 2013;5:1081-101. https://doi.org/10.3390/polym5031081.

[37] Casse O, Shkilnyy A, Linders J, Mayer C, Häussinger D, Völkel A, et al. Solution Behavior of Double-Hydrophilic Block Copolymers in Dilute Aqueous Solution. Macromolecules 2012;45:4772-7. https://doi.org/10.1021/ma300621g.

[38] Willersinn J, Schmidt BVKJ. Self-Assembly of Double Hydrophilic Poly(2-ethyl-2-oxazoline)-bpoly(N-vinylpyrrolidone) Block Copolymers in Aqueous Solution. Polymers 2017;9:293. https://doi.org/10.3390/polym9070293.

[39] Billing M, Festag G, Bellstedt P, Schacher FH. Amphiphilic and double hydrophilic block copolymers containing a polydehydroalanine block. Polym Chem 2017;8:936.

[40] Max JB, Mons PJ, Tom JC, Schacher FH. Double Hydrophilic Poly(ethylene oxide)- block Poly(dehydroalanine) Block Copolymers: Comparison of Two Different Synthetic Routes. Macromol Chem Phys 2020;221:1900383. https://doi.org/10.1002/macp.201900383.

[41] Oh T, Nagao M, Hoshino Y, Miura Y. Self-Assembly of a Double Hydrophilic Block Glycopolymer and the Investigation of Its Mechanism. Langmuir 2018;34:8591-8. https://doi.org/10.1021/acs.langmuir.8b01527.

[42] Savage AM, Ullrich E, Kost C, Turner SR. Salt- and pH-Responsive Semirigid/Flexible DoubleHydrophilic Block Copolymers. Macromol Chem Phys 2016;217:1737-44. https://doi.org/10.1002/macp.201600064.

[43] Gross RA, Kalra B. Biodegradable polymers for the environment. Science 2002;297:803. https://doi.org/10.1126/science.297.5582.803.

[44] Shukla RK, Tiwari A. Carbohydrate polymers: Applications and recent advances in delivering drugs to the colon. Carbohydr Polym 2012;88:399-416. https://doi.org/10.1016/j.carbpol.2011.12.021.

[45] Liu Z, Jiao Y, Wang Y, Zhou C, Zhang Z. Polysaccharides-based nanoparticles as drug delivery systems. Adv Drug Deliv Rev 2008;60:1650-62. https://doi.org/10.1016/j.addr.2008.09.001.

[46] Saravanakumar G, Jo DG, Park JH. Polysaccharide-Based Nanoparticles: A Versatile Platform for Drug Delivery and Biomedical Imaging. Curr Med Chem 2012;19:3212-29. https://doi.org/10.2174/092986712800784658.

[47] Dang JM, Leong KW. Natural polymers for gene delivery and tissue engineering. Adv Drug Deliv Rev 2006;58:487-99. https://doi.org/10.1016/j.addr.2006.03.001.

[48] Ratner BD, Bryant SJ. Biomaterials: Where We Have Been and Where We Are Going. Annu Rev Biomed Eng 2004;6:41-75. https://doi.org/10.1146/annurev.bioeng.6.040803.140027. 
[49] Chen J, Jo S, Park K. Polysaccharide hydrogels for protein drug delivery. vol. 28. 1995. https://doi.org/10.1016/0144-8617(95)00080-1.

[50] Mizrahy S, Peer D. Polysaccharides as building blocks for nanotherapeutics. Chem Soc Rev 2012;41:2623-40. https://doi.org/10.1039/C1CS15239D.

[51] Jain A, Gupta Y, Jain S. Perspectives of Biodegradable Natural Polysaccharides for Site-Specific Drug Delivery to the Colon. vol. 10. 2007.

[52] Zhang N, Wardwell P, Bader R. Polysaccharide-Based Micelles for Drug Delivery. Pharmaceutics 2013;5:329-52. https://doi.org/10.3390/pharmaceutics5020329.

[53] Y. Liu, J. Sun, P. Zhang and Z. He. Amphiphilic Polysaccharide-Hydrophobicized Graft Polymeric Micelles for Drug Delivery Nanosystems. Curr Med Chem 2011;18:2638-48. https://doi.org/10.2174/092986711795933696.

[54] Yang KW, Li XR, Yang ZL, Li PZ, Wang F, Liu Y. Novel polyion complex micelles for liver-targeted delivery of diammonium glycyrrhizinate: In vitro and in vivo characterization. J Biomed Mater Res A 2009;88A:140-8. https://doi.org/10.1002/jbm.a.31866.

[55] Park J-S, Koh Y-S, Bang J-Y, Jeong Y-I, Lee J-J. Antitumor Effect of All-Trans Retinoic AcidEncapsulated Nanoparticles of Methoxy Poly(Ethylene Glycol)-Conjugated Chitosan Against CT26 Colon Carcinoma In Vitro. J Pharm Sci 2008;97:4011-9. https://doi.org/10.1002/jps.21221.

[56] Mao S, Bakowsky U, Jintapattanakit A, Kissel T. Self-Assembled Polyelectrolyte Nanocomplexes between Chitosan Derivatives and Insulin. J Pharm Sci 2006;95:1035-48. https://doi.org/10.1002/jps.20520.

[57] Blanco-Fernandez B, Concheiro A, Makwana H, Fernandez-Trillo F, Alexander C, Alvarez-Lorenzo C. Dually sensitive dextran-based micelles for methotrexate delivery. RSC Adv 2017;7:1444860. https://doi.org/10.1039/C7RA00696A.

[58] Li N, Li X-R, Zhou Y-X, Li W-J, Zhao Y, Ma S-J, et al. The use of polyion complex micelles to enhance the oral delivery of salmon calcitonin and transport mechanism across the intestinal epithelial barrier. Biomaterials 2012;33:8881-92. https://doi.org/10.1016/j.biomaterials.2012.08.047.

[59] Ganji F, Abdekhodaie MJ. Synthesis and characterization of a new thermosensitive chitosanPEG diblock copolymer. Carbohydr Polym 2008;74:435-41. https://doi.org/10.1016/j.carbpol.2008.03.017.

[60] Moussa A, Crépet A, Ladavière C, Trombotto S. Reducing-end "clickable" functionalizations of chitosan oligomers for the synthesis of chitosan-based diblock copolymers. Carbohydr Polym 2019;219:387-94. https://doi.org/10.1016/j.carbpol.2019.04.078.

[61] Hernandez OS, Soliman GM, Winnik FM. Synthesis, reactivity, and pH-responsive assembly of new double hydrophilic block copolymers of carboxymethyldextran and poly(ethylene glycol). Polymer 2007;48:921-30. https://doi.org/10.1016/j.polymer.2006.12.036.

[62] Soliman GM, Winnik FM. Enhancement of hydrophilic drug loading and release characteristics through micellization with new carboxymethyldextran-PEG block copolymers of tunable charge density. Int J Pharm 2008;356:248-58. https://doi.org/10.1016/j.ijpharm.2007.12.029.

[63] Soliman GM, Choi AO, Maysinger D, Winnik FM. Minocycline Block Copolymer Micelles and their Anti-Inflammatory Effects on Microglia. Macromol Biosci 2010;10:278-88. https://doi.org/10.1002/mabi.200900259.

[64] Soliman GM, Szychowski J, Hanessian S, Winnik FM. Robust polymeric nanoparticles for the delivery of aminoglycoside antibiotics using carboxymethyldextran-b-poly(ethyleneglycols) lightly grafted with n-dodecyl groups. Soft Matter 2010;6:4504-14. https://doi.org/10.1039/COSM00316F.

[65] Brosnan SM, Schlaad H, Antonietti M. Aqueous Self-Assembly of Purely Hydrophilic Block Copolymers into Giant Vesicles. Angew Chem Int Ed 2015;54:9715-8. https://doi.org/10.1002/anie.201502100.

[66] Willersinn J, Schmidt BVKJ. Aqueous self-assembly of pullulan- $b$-poly(2-ethyl-2-oxazoline) double hydrophilic block copolymers. J Polym Sci Part Polym Chem 2017;55:3757-66. https://doi.org/10.1002/pola.28761. 
[67] Fischer D, Li Y, Ahlemeyer B, Krieglstein J, Kissel T. In vitro cytotoxicity testing of polycations: influence of polymer structure on cell viability and hemolysis. Biomaterials 2003;24:1121-31. https://doi.org/10.1016/S0142-9612(02)00445-3.

[68] Perry SL, Leon L, Hoffmann KQ, Kade MJ, Priftis D, Black KA, et al. Chirality-selected phase behaviour in ionic polypeptide complexes. Nat Commun 2015;6:6052. https://doi.org/10.1038/ncomms7052.

[69] Priftis D, Leon L, Song Z, Perry SL, Margossian KO, Tropnikova A, et al. Self-Assembly of $\alpha$-Helical Polypeptides Driven by Complex Coacervation. Angew Chem Int Ed 2015;54:11128-32. https://doi.org/10.1002/anie.201504861.

[70] Wu WZ, Cui SD, Li ZJ, Liu JJ, Wang HY, Wang X, et al. Mild Bronsted acid initiated controlled polymerizations of 2-oxazoline towards one-pot synthesis of novel double-hydrophilic poly(2ethyl-2-oxazoline)-block-poly(sarcosine). Polym Chem 2015;6:2970-6. https://doi.org/10.1039/c5py00256g.

[71] Salmanpour M, Tamaddon A, Yousefi G, Mohammadi-Samani S. "Grafting-from" synthesis and characterization of poly (2-ethyl-2-oxazoline)-b-poly (benzyl L-glutamate) micellar nanoparticles for potential biomedical applications. Biolmpacts 2017;7:155-66. https://doi.org/10.15171/bi.2017.19.

[72] Salmanpour M, Yousefi G, Samani SM, Mohammadi S, Anbardar MH, Tamaddon A. Nanoparticulate delivery of irinotecan active metabolite (SN38) in murine colorectal carcinoma through conjugation to poly (2-ethyl 2-oxazoline)-b-poly (L-glutamic acid) double hydrophilic copolymer. Eur J Pharm Sci 2019;136:104941. https://doi.org/10.1016/j.ejps.2019.05.019.

[73] Kasparova P, Antonietti M, Colfen H. Double hydrophilic block copolymers with switchable secondary structure as additives for crystallization control. Colloids Surf -Physicochem Eng Asp 2004;250:153-62. https://doi.org/10.1016/j.colsurfa.2004.03.033.

[74] Lee Y, Ishii T, Cabral H, Kim HJ, Seo J-H, Nishiyama N, et al. Charge-Conversional Polyionic Complex Micelles-Efficient Nanocarriers for Protein Delivery into Cytoplasm. Angew Chem Int Ed 2009;48:5309-12. https://doi.org/10.1002/anie.200900064.

[75] Takae S, Miyata K, Oba M, Ishii T, Nishiyama N, Itaka K, et al. PEG-detachable polyplex micelles based on disulfide-linked block catiomers as bioresponsive nonviral gene vectors. J Am Chem Soc 2008;130:6001-9. https://doi.org/10.1021/ja800336v.

[76] Li MQ, Lv SX, Tang ZH, Song WT, Yu HY, Sun H, et al. Polypeptide/Doxorubicin Hydrochloride Polymersomes Prepared Through Organic Solvent-free Technique as a Smart Drug Delivery Platform. Macromol Biosci 2013;13:1150-62. https://doi.org/10.1002/mabi.201300222.

[77] Nishiyama N, Nakagishi Y, Morimoto Y, Lai P-S, Miyazaki K, Urano K, et al. Enhanced photodynamic cancer treatment by supramolecular nanocarriers charged with dendrimer phthalocyanine. J Controlled Release 2009;133:245-51. https://doi.org/10.1016/j.jconrel.2008.10.010.

[78] Zhang G-D, Nishiyama N, Harada A, Jiang D-L, Aida T, Kataoka K. pH-sensitive Assembly of LightHarvesting Dendrimer Zinc Porphyrin Bearing Peripheral Groups of Primary Amine with Poly(ethylene glycol)-b-poly(aspartic acid) in Aqueous Solution. Macromolecules 2003;36:1304-9. https://doi.org/10.1021/ma025735y.

[79] Jang W-D, Nakagishi Y, Nishiyama N, Kawauchi S, Morimoto Y, Kikuchi M, et al. Polyion complex micelles for photodynamic therapy: Incorporation of dendritic photosensitizer excitable at long wavelength relevant to improved tissue-penetrating property. J Controlled Release 2006;113:73-9. https://doi.org/10.1016/j.jconrel.2006.03.009.

[80] Akai H, Shiraishi K, Yokoyama M, Yasaka K, Nojima M, Inoue Y, et al. PEG-poly(L-lysine)-based polymeric micelle MRI contrast agent: Feasibility study of a Gd-micelle contrast agent for MR lymphography: MR Lymphography by Gd-Micelle MRI Agent. J Magn Reson Imaging 2018;47:238-45. https://doi.org/10.1002/jmri.25740.

[81] Shiraishi K, Kawano K, Minowa T, Maitani Y, Yokoyama M. Preparation and in vivo imaging of PEG-poly(L-lysine)-based polymeric micelle MRI contrast agents. J Controlled Release 2009;136:14-20. https://doi.org/10.1016/j.jconrel.2009.01.010. 
[82] Wang C, Feng S, Qie J, Wei X, Yan H, Liu K. Polyion complexes of a cationic antimicrobial peptide as a potential systemically administered antibiotic. Int J Pharm 2019;554:284-91. https://doi.org/10.1016/j.ijpharm.2018.11.029.

[83] Dash TK, Konkimalla VB. Poly- $\epsilon$-caprolactone based formulations for drug delivery and tissue engineering: A review. J Controlled Release 2012;158:15-33. https://doi.org/10.1016/j.jconrel.2011.09.064.

[84] Zhang J, Xiao Y, Xu H, Zhou C, Lang M. Synthesis of well-defined carboxyl poly( $\varepsilon$-caprolactone) by fine-tuning the protection group. Polym Chem 2016;7:4630-7. https://doi.org/10.1039/C6PY00932H.

[85] Rainbolt EA, Washington KE, Biewer MC, Stefan MC. Recent developments in micellar drug carriers featuring substituted poly( $\varepsilon$-caprolactone)s. Polym Chem 2015;6:2369-81. https://doi.org/10.1039/C4PY01628A.

[86] Jing H, Elizabeth AR, Katherine W, Michael CB, Mihaela CS. Synthesis of Functionalized Poly(caprolactone)s and Their Application as Micellar Drug Delivery Systems. Curr Org Chem 2013;17:930-42. https://doi.org/10.2174/1385272811317090007.

[87] Lecomte P, Riva R, Schmeits S, Rieger J, Van Butsele K, Jérôme C, et al. New Prospects for the Grafting of Functional Groups onto Aliphatic Polyesters. Ring-Opening Polymerization of $\alpha$ - orySubstitutede-Caprolactone Followed by Chemical Derivatization of the Substituents. Macromol Symp 2006;240:157-65. https://doi.org/10.1002/masy.200650820.

[88] Ponsart S, Coudane J, Vert M. A Novel Route To Poly( $\varepsilon$-caprolactone)-Based Copolymers via Anionic Derivatization. Biomacromolecules 2000;1:275-81. https://doi.org/10.1021/bm005521t.

[89] Gautier S, D’Aloia V, Halleux O, Mazza M, Lecomte P, Jérôme R. Amphiphilic copolymers of $\varepsilon$ caprolactone and $\gamma$-substituted $\varepsilon$-caprolactone. Synthesis and functionalization of poly(D,Llactide) nanoparticles. J Biomater Sci Polym Ed 2003;14:63-85. https://doi.org/10.1163/15685620360511146.

[90] Mahmud A, Xiong X-B, Lavasanifar A. Novel Self-Associating Poly(ethylene oxide)-block-poly( $\varepsilon$ caprolactone) Block Copolymers with Functional Side Groups on the Polyester Block for Drug Delivery. Macromolecules 2006;39:9419-28. https://doi.org/10.1021/ma0613786.

[91] Mahmud A, Patel S, Molavi O, Choi P, Samuel J, Lavasanifar A. Self-Associating Poly(ethylene oxide)-b-poly( $\alpha$-cholesteryl carboxylate- $\varepsilon$-caprolactone) Block Copolymer for the Solubilization of STAT-3 Inhibitor Cucurbitacin I. Biomacromolecules 2009;10:471-8. https://doi.org/10.1021/bm800846a.

[92] de Gracia Lux C, Almutairi A. Intramolecular Cyclization for Stimuli-Controlled Depolymerization of Polycaprolactone Particles Leading to Disassembly and Payload Release. ACS Macro Lett 2013;2:432-5. https://doi.org/10.1021/mz400129h.

[93] Liu J, Zhang $\mathrm{Y}$, Yan J, Lang M. Synthesis and solution properties of $\mathrm{pH}$ responsive methoxy poly(ethylene glycol)-b-poly( $\gamma$-amino- $\varepsilon$-caprolactone). J Mater Chem 2011;21:6677-82. https://doi.org/10.1039/C1JM10142K.

[94] Charoongchit P, Suksiriworapong J, Sripha K, Mao S, Sapin-Minet A, Maincent P, et al. Selfaggregation of cationically modified poly( $\varepsilon$-caprolactone)2-co-poly(ethylene glycol) copolymers: Effect of cationic grafting ligand and poly( $\varepsilon$-caprolactone) chain length. Mater Sci Eng C 2017;72:444-55. https://doi.org/10.1016/j.msec.2016.11.043.

[95] Yang T, Hussain A, Bai S, Khalil IA, Harashima H, Ahsan F. Positively charged polyethylenimines enhance nasal absorption of the negatively charged drug, low molecular weight heparin. J Controlled Release 2006;115:289-97. https://doi.org/10.1016/j.jconrel.2006.08.015.

[96] Gao GH, Park MJ, Li Y, Im GH, Kim J-H, Kim HN, et al. The use of pH-sensitive positively charged polymeric micelles for protein delivery. Biomaterials 2012;33:9157-64. https://doi.org/10.1016/j.biomaterials.2012.09.016.

[97] Deng H, Liu J, Zhao X, Zhang Y, Liu J, Xu S, et al. PEG-b-PCL Copolymer Micelles with the Ability of $\mathrm{pH}$-Controlled Negative-to-Positive Charge Reversal for Intracellular Delivery of Doxorubicin. Biomacromolecules 2014;15:4281-92. https://doi.org/10.1021/bm501290t. 
[98] Li Y-M, Chang X-P, Cheng Y-J, Chen S, He F, Zhuo R-X. Mercaptan acids modified amphiphilic copolymers for efficient loading and release of doxorubicin. Colloids Surf B Biointerfaces 2017;153:220-8. https://doi.org/10.1016/j.colsurfb.2017.02.022.

[99] Zhang Y, Ni C, Shi G, Wang J, Zhang M, Li W. The polyion complex nano-prodrug of doxorubicin (DOX) with poly(lactic acid-co-malic acid)-block-polyethylene glycol: Preparation and drug controlled release. vol. 24. 2015. https://doi.org/10.1007/s00044-014-1206-7.

[100] Zhang J, Xiao Y, Luo X, Wen L, Heise A, Lang M. Schizophrenic poly( $\varepsilon$-caprolactone)s: synthesis, self-assembly and fluorescent decoration. Polym Chem 2017;8:3261-70. https://doi.org/10.1039/C7PY00461C.

[101] El Jundi A, Buwalda SJ, Bethry A, Hunger S, Coudane J, Bakkour Y, et al. Double-hydrophilic block copolymers based on functional poly( $\varepsilon$-caprolactone)s for $\mathrm{pH}$-dependent controlled drug delivery. Biomacromolecules 2019. https://doi.org/10.1021/acs.biomac.9b01006.

[102] Al Samad A, Bakkour Y, Fanny C, El Omar F, Coudane J, Nottelet B. From nanospheres to micelles: simple control of PCL-g-PEG copolymers' amphiphilicity through thiol-yne photografting. Polym Chem 2015;6:5093-102. https://doi.org/10.1039/C5PY00391A.

[103] Leroy A, Al Samad A, Garric X, Hunger S, Noël D, Coudane J, et al. Biodegradable networks for soft tissue engineering by thiol-yne photo cross-linking of multifunctional polyesters. RSC Adv 2014;4:32017-23. https://doi.org/10.1039/C4RA03665D.

[104] Zeynep EY, Antoine D, Brice C, Frank B, Christine J. Double hydrophilic polyphosphoester containing copolymers as efficient templating agents for calcium carbonate microparticles. $J$ Mater Chem B 2015;3:7227-36. https://doi.org/10.1039/C5TB00887E.

[105] Ergul Yilmaz Z, Cordonnier T, Debuigne A, Calvignac B, Jerome C, Boury F. Protein encapsulation and release from PEO-b-polyphosphoester templated calcium carbonate particles. Int J Pharm 2016;513:130-7. https://doi.org/10.1016/j.ijpharm.2016.09.007.

[106] Zhang P, Zhang Z, Yang Y, Li Y. Folate-PEG modified poly(2-(2aminoethoxy)ethoxy)phosphazene/DNA nanoparticles for gene delivery: Synthesis, preparation and in vitro transfection efficiency. Int J Pharm 2010;392:241-8. https://doi.org/10.1016/j.ijpharm.2010.03.030.

[107] Lim J, Matsuoka H, Saruwatari Y. Effects of Halide Anions on the Solution Behavior of Double Hydrophilic Carboxy-Sulfobetaine Block Copolymers. Langmuir 2020;36:5165-75. https://doi.org/10.1021/acs.langmuir.0c00325.

[108] Le Bohec M, Banère M, Piogé S, Pascual S, Benyahia L, Fontaine L. Sol-gel reversible metallosupramolecular hydrogels based on a thermoresponsive double hydrophilic block copolymer. Polym Chem 2016;7:6834-42. https://doi.org/10.1039/C6PY01639A.

[109] Díaz-Moscoso A, Ballester P. Light-responsive molecular containers. Chem Commun 2017;53:4635-52. https://doi.org/10.1039/C7CC01568B.

[110] He J, Yan B, Tremblay L, Zhao Y. Both Core- and Shell-Cross-Linked Nanogels: Photoinduced Size Change, Intraparticle LCST, and Interparticle UCST Thermal Behaviors. Langmuir 2011;27:43644. https://doi.org/10.1021/la1040322.

[111] Jin Q, Liu X, Liu G, Ji J. Fabrication of core or shell reversibly photo cross-linked micelles and nanogels from double responsive water-soluble block copolymers. Polymer 2010;51:1311-9. https://doi.org/10.1016/j.polymer.2010.01.026.

[112] Wu Y, Hu H, Hu J, Liu T, Zhang G, Liu S. Thermo- and Light-Regulated Formation and Disintegration of Double Hydrophilic Block Copolymer Assemblies with Tunable Fluorescence Emissions. Langmuir 2013;29:3711-20. https://doi.org/10.1021/la400145f.

[113] Tähkä S, Laiho A, Kostiainen MA. Diblock-Copolymer-Mediated Self-Assembly of ProteinStabilized Iron Oxide Nanoparticle Clusters for Magnetic Resonance Imaging. Chem - Eur J 2014;20:2718-22. https://doi.org/10.1002/chem.201304070.

[114] Li C, Hu J, Liu S. Engineering FRET processes within synthetic polymers, polymeric assemblies and nanoparticles via modulating spatial distribution of fluorescent donors and acceptors. Soft Matter 2012;8:7096. https://doi.org/10.1039/c2sm25582k. 
[115] Qiu X, Wang X, Hou S, Zhang J, Zhou J, Tan Y. Tunable Fluorescence-Responsive Double Hydrophilic Block Polymers Induced by the Formation of Pseudopolyrotaxanes with Cucurbit[7]Uril. Polymers 2019;11:1470. https://doi.org/10.3390/polym11091470.

[116] Jeong $\mathrm{H}$, Hwang J, Lee $\mathrm{H}$, Hammond PT, Choi J, Hong J. In vitro blood cell viability profiling of polymers used in molecular assembly. Sci Rep 2017;7. https://doi.org/10.1038/s41598-01710169-5.

[117] Shiraishi K, Yokoyama M. Toxicity and immunogenicity concerns related to PEGylated-micelle carrier systems: a review. Sci Technol Adv Mater 2019;20:324-36. https://doi.org/10.1080/14686996.2019.1590126.

[118] Garay RP, El-Gewely R, Armstrong JK, Garratty G, Richette P. Antibodies against polyethylene glycol in healthy subjects and in patients treated with PEG-conjugated agents. Expert Opin Drug Deliv 2012;9:1319-23. https://doi.org/10.1517/17425247.2012.720969. 